\title{
AVALIAÇÃO DAS PROPRIEDADES MECÂNICAS DE OSSOS DE COELHAS SUBMETIDAS À ADMINISTRAÇÃO DE GLICOCORTICÓIDES
}

Célio Anderson Silva Júnior

Dissertação apresentada ao Programa de PósGraduação Interunidades em Bioengenharia / Escola de Engenharia de São Carlos / Faculdade de Medicina de Ribeirão Preto / Instituto de Química de São Carlos, da Universidade de São Paulo para obtenção do título de Mestre em Bioengenharia.

Orientador: Prof. Dr. Antônio Carlos Shimano. 


\section{A Deus,}

Por ter me escolhido para mostrar que

"nada é impossível aos olhos do

Senhor." 


\section{Homenagem}

A Irene, mulher da minha vida, que Deus colocou no meu caminho no tempo certo; você é tudo o que sonhei pra mim; mulher que luta por seus ideais, mas ao mesmo tempo tem uma sensibilidade ímpar. Mãe zelosa, dedicada, agradeço àDeus por ter você conosco. Dedico a você todo o fruto vindouro desses anos de luta incessante, onde você acumulou as funções de mãe, dona de casa, esposa e foi financeiramente a mantenedora de nossa casa sem nos deixar faltar nada, através de sua exaustiva jornada de trabalho para poder permitir que eu concretizasse seu sonho, pois foi você quem me presenteou com esta oportunidade sem igual. Obrigado por ter acreditado e estado ao meu lado, administrando as dificuldades inerentes de tamanha ousadia, pois sonhar é fácil, mas difícil é colocá-lo em prática, e você sonhou com dias melhores para nós e ousou em vê-los realizados. Essa vitória é sua. Obrigado por não deixar eu desistir. TE AMO.

Aos meus filhos Leopoldo e Thales. Vocês são fontes inesgotáveis de estímulos. Obrigado Senhor por ter me dado presentes tão preciosos. 


\section{Agradecimentos}

Ao meu orientador Prof. Dr. Antônio Carlos Shimano, por ter acreditado neste trabalho e depositado sua confiança em mim. Obrigado pela paciência, dedicação e pelos ensinamentos adquiridos. Agradeço ainda a você e sua família por ter nos acolhido como se fizéssemos parte da mesma. Temos uma dívida eterna com vocês. Caro Professor, nos momentos em que trabalhamos juntos, fui tratado como um filho sendo incentivado e corrigido quando se fez necessário, mas sempre de maneira construtiva. Não existe palavra para expressar meus agradecimentos.

Ao Prof. Dr. José Batista Portugal Paulin, chefe do Laboratório de Bioengenharia de Ribeirão Preto, pela compreensão e disponibilização do laboratório para desenvolvimento desta pesquisa.

Ao Prof. Dr. José B. Volpon pela ajuda preciosa no momento importante para a concretização desta pesquisa, mostrando os caminhos a seguir e disponibilizando a Máquina Universal de Ensaio EMIC ®. Meu muito obrigado!

Ao Marcos M. Shimano pela contribuição com seu conhecimento em informática.

Aos amigos que no momento mais delicado deste trabalho, abdicaram de seu precioso tempo para se juntarem em um só objetivo: ver a concretização deste trabalho. Obrigado Fabrício Borges Oliveira, Leonardo César Carvalho, Gustavo Silva Abrahão.

Aos bibliotecários da UNESP de llha Solteira, e meus compadres, João e Célia, obrigados por tudo que têm feito por nós. 
Aos técnicos e amigos do Laboratório de Bioengenharia, Francisco Carlos Mazzocato e Luís Henrique Alves Pereira por serem sempre prestativos.

Ao amigo Vítor Aparecido Castania e sua família que se mostraram solidários nesta conquista.

As secretárias Maria Teresinha Moraes e Janete Ferreira Rodrigues dos Santos que muito contribuem para que o programa de Pós Graduação em Bioengenharia funcione bem.

Ao Prof. Dr. José Antônio Badinni Martinez, e suas orientandas Irene Raimundo dos Santos Silva e Elaine Caetano Silva por terem permitido trabalharmos em equipe, utilizando os mesmos animais de suas pesquisas.

A todos que direta ou indiretamente contribuíram para a realização deste trabalho. 
As normas de apresentação desta dissertação obedecem àquelas estabelecidas pela Universidade de São Paulo, 2001. 


\section{SUMÁRIO}

LISTA DE FIGURAS ....................................................................

LISTA DE ABREVIATURAS, SIGLAS E SÍMBOLOS................. iv

RESUMO.............................................................................. V

ABSTRACT ........................................................................ vii

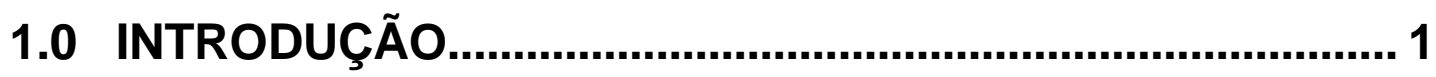

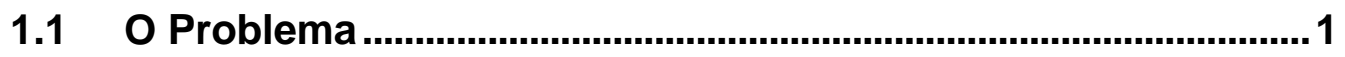

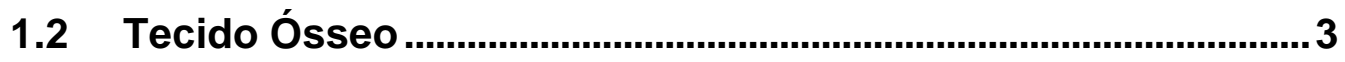

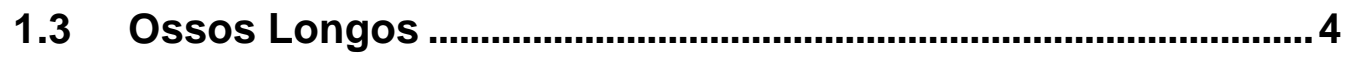

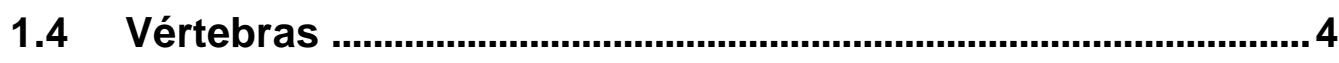

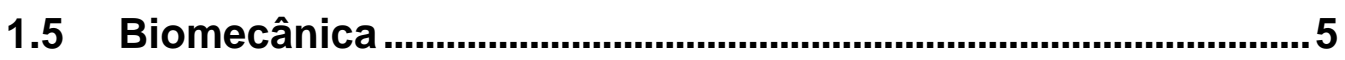

1.6 Ensaios Mecânicos de Flexão de Compressão em Ossos .....6

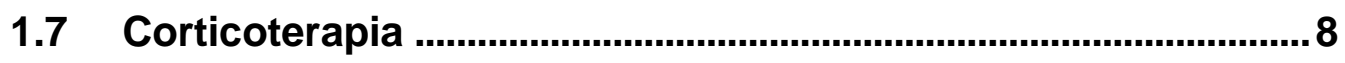

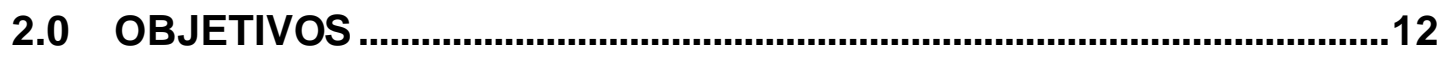

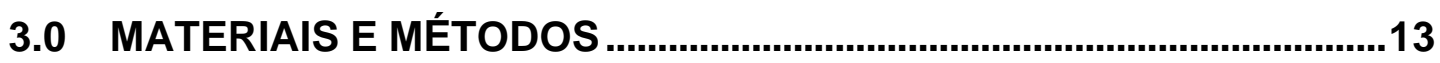

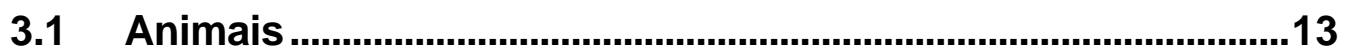

3.2 Grupos de Animais ......................................................................14

3.3 Protocolo de Administração do Medicamento .........................15

3.4 Preparo das Peças ......................................................................16

3.4.1 Confecção dos Corpos de Prova (CDPs)...........................17

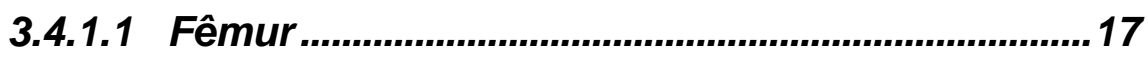

3.4.1.2 Vértebras................................................................18

3.5 Ensaios Mecânicos de Flexão das Tíbias e Fêmures ..............20

3.6 Ensaios Mecânicos de Flexão em CDPs em Fêmures ............22

3.7 Ensaios Mecânicos de Compressão em Vértebras .................24

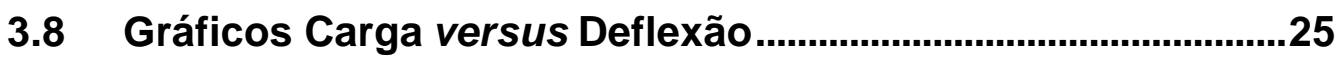




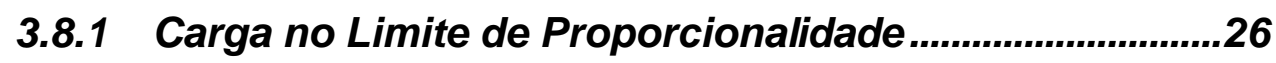

3.8.2 Deformação no Limite de Proporcionalidade .................26

3.8.3 Rigidez..................................................................................26

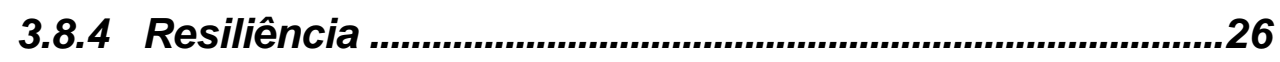

3.8.5 Carga e Deflexão Máxima .................................................27

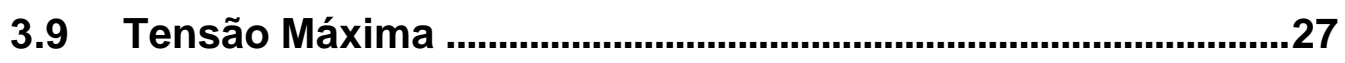

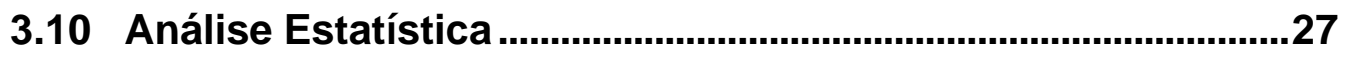

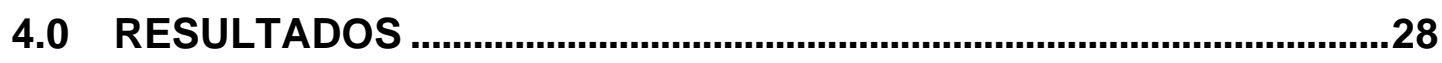

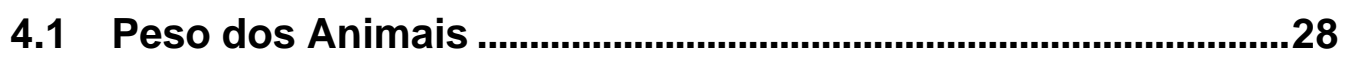

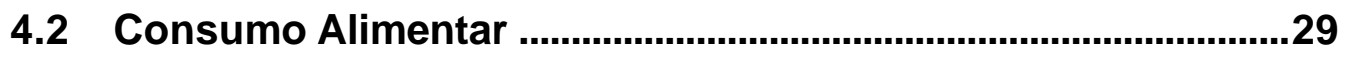

4.3 Medidas Antropométricas e Propriedades Mecânicas das Tíbias como Estrutura .............................................................................30

4.3.1 Peso da Tíbia ...................................................................31

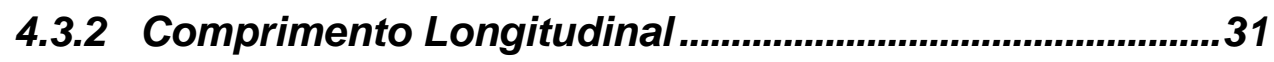

4.3.3 Comprimento Circunferencial.........................................32

4.3.4 Gráficos Carga versus Deflexão........................................33

4.3.4.1 Deflexão no Limite de Proporcionalidade .........35

4.3.4.2 Carga no Limite de Proporcionalidade ................36

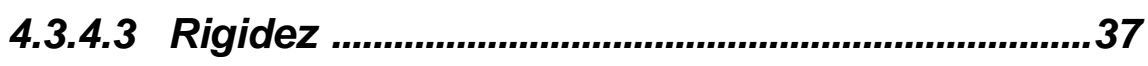

4.3.4.4 Carga Máxima ........................................................38

4.3.4.5 Resiliência ...............................................................39

4.4 Medidas Antropométricas e Propriedades Mecânicas dos

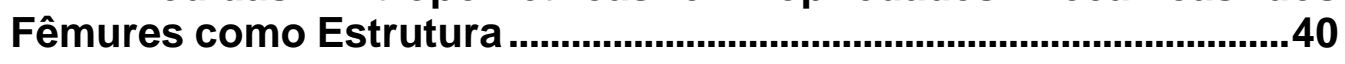

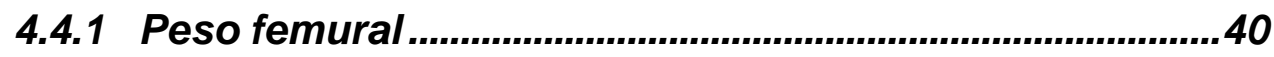

4.4.2 Comprimento Longitudinal ...............................................41

4.4.3 Comprimento Circunferencial...........................................42

4.4.4 Gráficos Carga versus Deflexão........................................43

4.4.4.1 Deflexão no Limite de Proporcionalidade ...........44

4.4.4.2 Carga no Limite de Proporcionalidade .................45

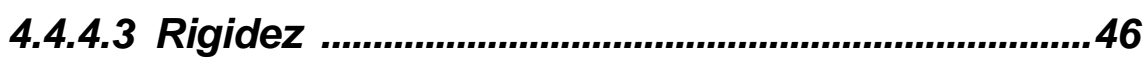

4.4.4.4 Carga Máxima .............................................................47 
4.4.4.5 Resiliência 48

4.5 Avaliação dos Ossos como Material. .49

4.5.1 Análise Qualitativa da Arquitetura Trabecular .49

4.5.2 Tensão Máxima dos CDPs de fêmures. .51

4.5.3 Tensão Máxima dos CDPs das vértebras .52

5.0 DISCUSSÃO. .53

6.0 CONCLUSÃO .61

7.0 ANEXOS .62

8.0 REFERÊNCIAS BIBLIOGRÁFICAS .73 


\section{LISTA DE FIGURAS}

FIGURA 1 - Fêmur marcado para a obtenção de CDP.................................17

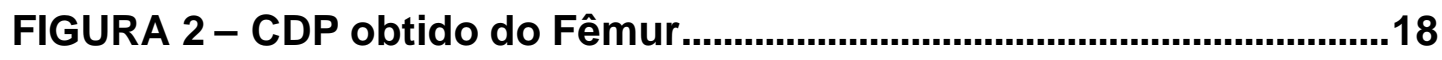

FIGURA 3 - Vértebra posicionada para o primeiro corte de $0,5 \mathrm{~mm}$.......19

FIGURA 4 - (A) Vértebra e (B) CDP obtido da vértebra ............................19

FIGURA 5 - Tíbia posicionada para realização do ensaio de flexão........21

FIGURA 6 - (A) Fêmur e (B) Tíbia bi-apoiados sobre o acessório ...........22

FIGURA 7 - (A) CDP do fêmur bi-apoiado sobre o acessório e

(B) acessório para a aplicação da carga ...............................................23

FIGURA 8 - (A) Acessório especial e (B) CDP obtido da vértebra ..........24

FIGURA 9 - Gráfico da carga versus deflexão, ilustrando o limite de proporcionalidade (LP), a reta que representa a inclinação da curva

$(\theta)$ e o triângulo formado pela união dos pontos de início do ensaio e LP. A letra $\underline{h}$ representa a altura, $\underline{b}$ a base e $\underline{a}$ área do referido triângulo .25

FIGURA 10 - Representa os valores médios do peso inicial e final dos animais do grupo experimental e controle .29

FIGURA 11 - Valores médios de consumo alimentar entre os grupos experimentais e controles

FIGURA 12 - Valores médios dos pesos das tíbias dos subgrupos experimental (GE1T) e controle (GC1T)

FIGURA 13 - Valores médios dos comprimentos longitudinais das tíbias do subgrupo experimental (GE1T) e controle (GC1T) .32 FIGURA 14 - Valores médios dos comprimentos circunferenciais das tíbias do subgrupo experimental (GE1T) e controle (GC1T) obtidas da região central da diáfise óssea. .33

FIGURA 15 - Gráfico das curvas carga versus deflexão de 12 tíbias do subgrupo experimental (GE1T). .34

FIGURA 16 - Gráfico das curvas carga versus deflexão de 12 tíbias do subgrupo controle (GC1T). 
FIGURA 17 - Valores médios das deflexões no limite de proporcionalidade das tíbias dos subgrupos experimental (GE1T) e controle (GC1T)

FIGURA 18 - Valores médios das cargas aplicadas no limite de proporcionalidade das tíbias dos subgrupos experimental (GE1T) e controle (GC1T)

FIGURA 19 - Valores médios da rigidez das tíbias dos subgrupos experimental (GE1T) e controle (GC1T)

FIGURA 20 - Valores médios das cargas aplicadas máximas nas tíbias do subgrupo experimental (GE1T) e controle (GC1T).

FIGURA 21 - Valores médios da resiliência das tíbias do subgrupo experimental (GE1T) e controle (GC1T)

FIGURA 22 - Valores médios dos pesos dos fêmures do subgrupo experimental (GE1F) e controle (GC1F)

FIGURA 23 - Valores médios do comprimento dos fêmures do subgrupo experimental (GE1F) e controle (GC1F)

FIGURA 24 - Valores médios do comprimento dos fêmures do subgrupo experimental (GE1F) e controle (GC1F)

FIGURA 25 - Gráficos das curvas carga versus deflexão dos 12 fêmures do subgrupo experimental (GE1F). .43

FIGURA 26 - Gráficos das curvas carga versus deflexão dos 12 fêmures do subgrupo controle (GC1F) .43

FIGURA 27 - Valores médios das deflexões no limite de proporcionalidade dos fêmures dos subgrupos experimental (GE1F) e controle (GC1F)

FIGURA 28 - Valores médios das cargas no limite de proporcionalidade dos fêmures dos subgrupos experimental (GE1F) e controle (GC1F).

FIGURA 29 - Valores médios da rigidez dos fêmures dos subgrupos experimental (GE1F) e controle (GC1F) 
FIGURA 30 - Valores médios das cargas máximas dos fêmures dos subgrupos experimental (GE1F) e controle (GC1F)

FIGURA 31 - Valores médios da resiliência dos fêmures dos subgrupos experimental (GE1F) e controle (GC1F)

FIGURA 32- (A) CDP da vértebra do subgrupo GC2V antes da realização do ensaio mecânico. A barra de medida representada na figura indica a dimensão de comprimento de 0,7 $\mathrm{mm}$. (B) CDP da vértebra do subgrupo GE2V antes da realização do ensaio mecânico. A barra de medida representada na figura indica a dimensão de comprimento de $0,6 \mathrm{~mm}$. . .50

FIGURA 33- (A) CDP da vértebra do subgrupo GC2V após a realização do ensaio mecânico. A barra de medida representada na figura indica a dimensão de comprimento de $0,6 \mathrm{~mm}$. (B) CDP da vértebra do subgrupo GE2V após a realização do ensaio mecânico. $A$ barra de medida representada na figura indica a dimensão de comprimento de $0,7 \mathrm{~mm}$

FIGURA 34 - Valores médios das tensões máximas dos fêmures dos subgrupos experimental (GE2F) e controle (GC2F)

FIGURA 35 - Valores médios das tensões máximas das vértebras dos subgrupos experimental (GE2V) e controle (GC2V). .52 


\section{LISTA DE ABREVIATURAS, SIGLAS E SÍMBOLOS}

cm - centímetros

FMRP - Faculdade de Medicina de Ribeirão Preto

g - gramas

J - Joule

Kg - Quilogramas

$\mathrm{mg} / \mathrm{Kg}$ - miligramas por quilogramas

LP - Limite de proporcionalidade

m - metro

mg - Miligramas

ml - Mililitros

mm - milímetros

MPa - Mega pascal

Kgf - kilograma força

N - Newton

SA - Sociedade Anônima

USP - Universidade de São Paulo 


\section{RESUMO}

SILVA JUNIOR, C. A. Avaliação das propriedades mecânicas de ossos de coelhas submetidas à administração de glicocorticóides, 2003. 76p. Dissertação (Mestrado) - Escola de Engenharia de São Carlos/Faculdade de Medicina de Ribeirão Preto/Instituto de Química de São Carlos, Universidade de São Paulo, Ribeirão Preto.

O corticóide é usado nas várias especialidades médicas por ser um fármaco de potente efeito anti-inflamatório e imunossupressor, no entanto, é capaz de produzir algumas alterações metabólicas quando administrado por uso prolongado. Desta forma o presente estudo teve como objetivo avaliar as possíveis alterações nas propriedades mecânicas de osso cortical e trabecular de coelhas albinas, quando submetidas à administração de corticoesteróide em altas doses e por tempo prolongado, através de ensaio mecânico de flexão em três pontos em tíbia e fêmures avaliados como estrutura, além de ensaios mecânicos em corpos de prova por flexão em três pontos em fêmures e compressão em vértebras (L5). Para o estudo foram utilizados 39 animais, divididos aleatoriamente em dois grupos, experimental (GE) e controle (GC). Estes grupos foram divididos em quatro subgrupos, sendo 2 experimentais e 2 controles. $\mathrm{Na}$ investigação estrutural foram avaliadas as tíbias e fêmures direito por ensaios mecânicos de flexão em 3 pontos, e na investigação como material foram realizados ensaios mecânicos de flexão em 3 pontos para fêmures e compressão para vértebras (L5) através de corpos de prova. A metodologia utilizada para esta pesquisa foi igual para todos os animais, no entanto, o grupo experimental foi administrado durante 21 dias com o medicamento metilprednisolona (Solumedron ${ }^{\circledR}$ ) diluída em solução salina numa proporção de $2 \mathrm{mg} / \mathrm{Kg} / \mathrm{dia}$, e - grupo controle foi somente administrada solução salina na mesma dosagem. Todos os ensaios mecânicos foram realizados na Máquina Universal de Ensaio do Laboratório de Bioengenharia - FMRP/USP. Durante os ensaios foram registrados os valores das deflexões e as respectivas cargas aplicadas, sendo posteriormente confeccionadas curvas carga versus 
deflexão para cada osso ensaiado. As propriedades mecânicas determinadas para os fêmures e tíbias analisadas de forma estrutural foram: a carga aplicada no limite de proporcionalidade, deflexão no limite de proporcionalidade, carga máxima, rigidez e a resiliência de cada osso. Já para os fêmures e vértebras analisados como material ósseo, foram avaliados suas tensões máximas através da curva carga versus deflexão. Comparações estatísticas foram realizadas entre os resultados encontrados, através do teste T-Student, com nível de significância estabelecido em 5\% para todos os parâmetros analisados. Nas análises estatísticas entre os grupos investigados não foram observadas diferenças significativas em nenhuma das comparações, porém observou-se ao final deste estudo uma perda de peso corporal significativa do grupo experimental. Desta forma foi evidenciado através dos resultados encontrados nesta pesquisa que as propriedades mecânicas investigadas não apresentaram alterações significativas com o protocolo de administração de medicamento, sugerindose que novos experimentos sejam realizados, com modificações de dosagem e tempo de aplicação.

\section{Palavras-chave : Corticosteróide, Tíbia, Fêmur, Vértebras, Ensaio de flexão e Compressão.}




\section{ABSTRACT}

SILVA JUNIOR, C. A. Evaluation of Mechanical Properties of the Bone's of Rabbits Induced Glucocorticoid Administration . 2003. 76p. (Master Degree's) - São Carlos Engineering School/Ribeirão Preto Medicine College/ São Carlos Chemical Institute, São Paulo University, Ribeirão Preto.

Corticoteroids are used in many clinical conditions because they present strong anti-inflammatory and imunessupressor activities. But, at the same time, they can cause many metabolic alterations and side effects mainly when there is prolonged. In the present research we studied the possible alterations caused by steroids on the mechanical properties of lamellar and trabecular bone of rabbits. The mechanical properties were assessed by bending tests performed on intact femurs and tibial as well as in samples of cortical bone. Compression tests were performed in $L_{5}$ vertebral. Thirty-seven female rabbits were randomly distributes in one experimental group (EG-animals) and control (CG animals). Such groups were divided into four subgroups: two experimentals and two controls. The experimental animals received $2 \mathrm{mg} / \mathrm{kg} /$ day of methylprednisolone (Solumedron ${ }^{\circledR}$ ) during three weeks. The control animals received the same volume of intramuscular injections of saline, once a day, during three weeks. From the load $x$ deformation curves the load and deflexion were obtained at the yielding point. The ultimate load as well as resilience were also obtained for the intact bones. When the specimens were analysed the ultimate tension was determined. The statisitical analyses did not show any difference between treated and untreated animals for the mechanical properties. But the treated animals showed a significant loose of body weight. We ful that such results require a deepening in the investigation.

Key-words: Corticosteroids, Tibia, Femur, Vertebrae, Bend and Compression test. 


\section{0 - INTRODUÇÃO}

\section{1 - O Problema}

A osteoporose é um problema de saúde pública importante e cada vez mais acomete homens e mulheres. É uma afecção caracterizada por perda de massa óssea e deteriorização de sua microarquitetura e resulta em fraturas após traumatismo mínimo. Os locais de fratura característicos são os corpos vertebrais, o terço distal do rádio, e o terço proximal do fêmur, caracterizado como osso trabecular, porém, as pessoas osteoporóticas apresentam fragilidade esquelética generalizada e fraturas em outros locais, como o osso cortical de ossos longos, (GILMAN, 1996).

Vários investigadores têm demonstrado que as propriedades mecânicas e metabólicas do osso variam de acordo com o estado nutricional, idade, sexo, espécies e fases do crescimento (FONTOURA FILHO, 1995). Temos ainda que considerar as alterações das propriedades mecânicas de origem patológica e farmacológica como, por exemplo, as alterações causadas pelo uso prolongado e em altas doses de um determinado medicamento.

A osteoporose é a doença óssea metabólica mais comum, e é causa significativa de morbidade nos pacientes idosos. A perda da massa óssea principalmente do osso trabecular, caracteriza a osteoporose do tipo I.

Este tipo está relacionado com as alterações hormonais da menopausa e é responsável pela morbidade ligada æ̀ fraturas e desabamento vertebral. Um outro tipo comum e clinicamente desafiante de 
osteoporose é a observada em pacientes que utilizam tratamento crônico a base de glicocorticóides, (LANNA, 2003).

Lloyd et al., (2001), relataram o caso de uma mulher de 52 anos com artrite reumatóide, que foi tratada com baixas doses de esteróides, e que sofreu fratura bilateral da região distal de tíbia e fibula. Estes autores não encontraram evidência de osteopenia nestes ossos, e concluíram que embora a paciente tenha utilizado corticoterapia por longa data, as baixas doses utilizadas não alteraram a densidade óssea da tíbia e da fíbula apesar desses ossos terem sofrido fratura espontânea.

Orstavik et al., (2003), realizaram um estudo com 229 mulheres com artrite reumatóide, com o objetivo de avaliar a ocorrência de deformidade vertebral, a relação entre deformidade vertebral e a densidade óssea mineral, e entre deformidades vertebrais e variáveis clínicas através de exames radiológicos. Segundo a análise estatística, 49 pacientes apresentaram relevantes deformidades vertebrais. Estes autores concluíram ainda que há uma relação entre corticosteróides e o desenvolvimento de osteoporose em paciente portador de artrite reumatóide.

Bhattoa et al., (2002) realizou um estudo para determinar a prevalência da redução da densidade óssea mineral em um grupo de mulheres portadoras de Lupús Eritematoso Sistêmico, no período pré e pós menopausa, afim de identificar os fatores que predispõem a redução da densidade óssea mineral. Eles detectaram que a diminuição da densidade mineral óssea da coluna lombar têm uma significante correlação com o uso de altas doses de corticosteróides administrados diariamente. Quando comparado $\circ$ grupo que recebeu doses menores que $7,5 \mathrm{mg} / \mathrm{dia}$ com 0 grupo que recebeu doses maiores que $7,5 \mathrm{mg} / \mathrm{dia}$, constatou-se uma diminuição significativa da densidade óssea mineral da coluna lombar no grupo que recebeu maior dose.

Estes autores compararam ainda a densidade mineral óssea do colo do fêmur entre o grupo que recebeu doses maiores que $7,5 \mathrm{mg} / \mathrm{dia}$ comparado com o grupo que não recebeu corticóides e evidenciaram uma 
diferença significativa da densidade mineral óssea do colo do fêmur no grupo que recebeu doses maiores que $7,5 \mathrm{mg} / \mathrm{dia}$.

Segundo Gilman, (1996), a osteoporose secundária pode ocorrer devido a uma enfermidade sistêmica ou a medicamentos como os glicocorticóides, e pode acometer tanto o osso trabecular como o cortical.

Ainda, segundo Lanna et al., (2003), na osteoporose induzida por glicocorticóides, pode se observar a redução tanto da espessura da cortical óssea quanto do volume do osso trabecular.

\section{2 - Tecido Ósseo}

O desenvolvimento inicial do osso ocorre pela transformação do tecido conjuntivo do embrião. Quando os tecidos embrionários ainda são de mesoderma indiferenciado (mesênquima), ocorre um processo relativamente simples, conhecido por ossificação intramembranosa. Se as células mesodérmicas se transformam em células reprodutoras de cartilagem antes do início da formação do osso, o processo é mais complexo e é conhecido por ossificação endocondral, (SPENCE, 1991).

O tecido ósseo é constituído por tecido conjuntivo especial, sendo este formado por células e material extracelular calcificado, chamado de matriz óssea. A parte celular é composta por osteócitos, situado em lacunas no interior da matriz; por osteoblastos, que são os produtores orgânicos da matriz como, o colágeno tipo I, proteoglicanas e glicoproteínas adesivas e os osteoclastos que são células gigantes, móveis e multinucleadas, responsáveis pela reabsorção e remodelação óssea. Por ser a matriz óssea calcificada e sem possibilidade de difusão de substâncias, a nutrição dos osteócitos se dá através dos canalículos que se situam na matriz, possibilitando assim, as trocas de íons e moléculas entre os osteócitos e os capilares sangüíneos. (JUNQUEIRA \& CARNEIRO, 1999). 
O esqueleto desempenha várias funções importantes ao nosso organismo. Ele suporta todo o arcabouço do corpo, atuando como ponto de fixação para a maioria dos músculos, dando movimento e sustentação aos tecidos moles. $O$ esqueleto também protege as vísceras vulneráveis como, por exemplo, o crânio para o cérebro; a coluna vertebral para a medula espinhal e a caixa torácica para o coração e pulmão. $O$ osso na sua totalidade serve também para duas funções adicionais que são de tecido hematopoiético do tipo

mielóide para a produção de eritrócitos, granulócitos e plaquetas e como estoque de reserva para o cálcio, fósforo, magnésio e sódio. (HAMILL \& KNUTZEN,1999; SPENCE 1991; SALTER, 1985).

\section{3 - Ossos Longos}

Os ossos do corpo humano se classificam de acordo com sua forma, em: curtos, longos, planos e irregulares. A tíbia e o fêmur, dois dos ossos escolhidos para esta pesquisa são considerados ossos longos do membro inferior por ser mais comprido do que largo. Ao observar macroscopicamente um osso longo, este apresenta uma diáfise constituída por um tipo de osso cortical ou compacto e suas extremidades, são constituídas por osso trabecular ou esponjoso, (SOBOTTA, 1995).

\section{4. - Vértebras}

A coluna vertebral tem como função principal servir como eixo de suporte ao corpo, prover fixação para cabeça, tórax e cintura pélvica. Sua arquitetura permite que o tronco tenha considerável flexibilidade, protegendo a medula espinhal. Os ossos da coluna vertebral são classificados como irregular. O corpo vertebral, por exemplo, vértebra lombar L5, é formado 
basicamente por um corpo, um processo espinhoso, 2 processos transversos e seus processos articulares inferior e superior, (SPENCE, 1991). Geralmente, os esforços principais que as vértebras são submetidas são de compressão.

\section{5 - Biomecânica}

A biomecânica foi desenvolvida na área biológica a partir de estudos na área da física, mecânica e estudos das forças atuando sobre um objeto. A mecânica é usada por engenheiros para elaborar e construir estruturas como pontes, ou máquinas como aviões, já que oferece as ferramentas para analisar a força das estruturas e o modo de prever e medir o movimento de uma máquina. Foi um processo natural usar as ferramentas da mecânica e aplicá-las aos organismos vivos. Assim desenvolveu-se a biomecânica, o estudo da aplicação da mecânica aos sistemas biológicos. A biomecânica avalia o movimento de um organismo vivo e o efeito das forças sobre esse organismo (HALL, 1991). A abordagem biomecânica para análise dos movimentos pode ser qualitativa, com o movimento e a força observada e descrita, ou quantitativa, significando que está sendo feita alguma medida do movimento e da força, (HAMILL \& KNUTZEN, 1999).

O termo biomecânica foi adotado no início da década de 70 como uma definição, internacionalmente reconhecida, do campo de estudo relacionado com a análise mecânica dos organismos vivos. Foi definida como o estudo da estrutura e da função dos sistemas biológicos utilizando os métodos da mecânica.

Através dos ensaios mecânicos pode-se determinar as propriedades mecânicas de um material seja ele na forma de corpo de prova ou de uma estrutura íntegra. Os ensaios podem ser classificados de acordo com a forma e a direção das forças aplicadas. Neste caso, têm-se os ensaios de: tração, compressão, flexão, cisalhamento, torção e a 
combinação destes. Todos estes ensaios promovem a inutilização do material testado, sendo assim, conhecido também por ensaios destrutivos (SOUZA, 1977).

O conhecimento das propriedades mecânicas de cada parte da estrutura óssea é essencial ao ortopedista e para os profissionais da área de pesquisa e desenvolvimento como, por exemplo, de novas técnicas de tratamento de fraturas e de novas próteses. O osso é um material biológico e por isto deve existir uma relação entre os processos físicos e biológicos.

Portanto, o conhecimento da complexidade de sua estrutura e principalmente das propriedades mecânicas são importantes (SHIMANO \& SHIMANO, 2000).

\section{6 - Ensaios Mecânicos de Flexão e Compressão}

\section{em Ossos}

Do ponto de vista mecânico, o osso pode ser estudado como material ou como estrutura intacta; ambos os estudos têm finalidades distintas (EVANS, 1965). Dependendo do ensaio, pode-se determinar propriedades como: módulo de elasticidade, resiliência e limite de ruptura. Esses parâmetros são importantes, pois ajudam a caracterizar um elemento biológico que tem grande importância na absorção, transmissão e resistência a esforços físicos. Entretanto, o que se observa da literatura é que há grande variação de resultados, que dependem do osso utilizado, da região do osso (epífise, metáfise ou diáfise) e das condições em que a amostra foi obtida e conservada, do tipo de tratamento e do animal utilizado no estudo (SEDLIN \& HIRSCH, 1966). Essas variações, em parte, também advêm do fato de que o osso é um material viscoelástico, heterogêneo e anisotrópico (REILLY \& BURSTEIN, 1974; SEDLIN \& HIRSCH, 1966). 
O estudo do osso como estrutura intacta é interessante, pois os resultados refletem melhor a capacidade do sistema músculo-esquelético in vivo, sua função como alavanca e a capacidade para resistência aos esforços, em várias condições (HAYES \& CARTER, 1971).

O estudo da biomecânica em tecido ósseo portanto tem-se revelado de extrema importância para que se consiga determinar como e porque acontecem os eventos patológicos no mesmo, possibilitando assim prevenir ou tratar um distúrbio ou patologia com maior eficiência.

Silva (2002) realizou ensaio de flexão em três pontos em tíbias de ratas, avaliando algumas propriedades mecânicas das tíbias quando submetidas a um efeito de microgravidade. Foram utilizadas 55 ratas, sendo que 10 ratas foram utilizadas para o grupo controle e as demais divididas em grupos de 15 animais cada, onde permaneciam suspensos pela cauda, por períodos de 7, 14, e 21 dias respectivamente. Esta autora concluiu após os ensaios em flexão em três pontos das tíbias, que a simulação da microgravidade promoveu reduções significativas nos valores das propriedades mecânicas levando os ossos a um enfraquecimento.

Pessan em 1996 realizou ensaio de flexão em três pontos em fêmures de ratas, aplicando a carga na direção das faces no sentido anteroposterior, em duas fases diferentes de crescimento. Foram utilizadas 80 ratas divididas em 4 grupos de 20 animais cada. Os animais do primeiro e segundo grupo tinham 25 dias de idade, diferenciando apenas o local de aplicação de carga, sendo o primeiro na face anterior e o segundo na face posterior. No terceiro e quarto grupo seguiu-se a mesma metodologia que 0 primeiro e segundo, diferenciando apenas na idade que era de 79 dias. Conclui-se que os fêmures das ratas com idades maiores têm maior resistência mecânica aos esforços de flexão e que não foi observada diferença estatística significativa quando a força foi aplicada na concavidade ou convexidade do osso. 


\section{7 - Corticoterapia}

O uso da corticoterapia na área médica é grande em função de sua potente ação anti-inflamatória e imunossupressora. Em conseqüência, o uso da corticoterapia geralmente é indicado em várias patologias inflamatórias crônicas nas diversas áreas de saúde.

Em 1948, Hench utilizou cortisol na artrite reumatóide e relatou os efeitos que esta droga proporcionava no sentido de melhora significativa dos sintomas dessa patologia, porém na mesma época foram reconhecidos os efeitos colaterais associado a esse tipo de terapia. Sabemos hoje que entre essas reações indesejáveis do uso crônico de corticosteróides destacam-se a: osteoporose, hiperglicemia, supressão da resposta a infecção, atrofia muscular entre outros. (GILMAN, 1996).

O nosso organismo produz o hormônio chamado cortisol ou hidrocortisona, através da glândula supra adrenal, com a função de interromper ou minimizar um processo infeccioso instalado no organismo, mas muitas vezes essa quantidade produzida é insuficiente, levando o paciente a condições mórbidas e até mesmo a óbito. Em decorrência disso, muitas pesquisas foram realizadas pelas indústrias farmacêuticas para sintetizar esse hormônio em laboratório. Em 1946 o hormônio cortisol foi sintetizado com sucesso. Com isto houve um avanço nas pesquisas para se conseguir uma dosagem mais segura e duradoura, e com menos efeitos colaterais. Esta descoberta propiciou um importante avanço na medicina levando seus descobridores a ganharem o Prêmio Nobel de Medicina tamanha a importância da descoberta da síntese do cortisol. Contudo, ainda assim, alguns efeitos colaterais indesejáveis como a osteoporose, ainda permanecem quando se faz uso da corticoterapia por período prolongado e em altas doses.

Os glicocorticóides quando produzidos em excesso ou administrado por via sistêmica, com finalidade terapêutica como supressão da resposta alérgica, inflamatória e/ou imunológica, apresentam efeitos não desejados e adversos, como retenção hidrosalina e a espoliação de cálcio, 
potássio e hidrogênio, podendo ainda provocar o antagonismo ao hormônio de crescimento.

A homeostase óssea envolve um balanço entre os processos contínuos de formação e reabsorção óssea. A osteoporose induzida pelos glicocorticóides está associada por efeitos patogênicos em ambos os processos. Com isto, há inibição da formação óssea e estímulo ao processo de reabsorção (RAISZ et al., 1994).

Entre vários efeitos metabólicos causados pela terapia com corticosteróides, está a diminuição da musculatura esquelética (GILMAN, 1996), podendo ocorrer ainda a inibição da síntese das fibras de tecido conjuntivo, importantes nos processos de cicatrização das feridas (JUNQUEIRA \& CARNEIRO, 1999), e no tecido esquelético pode ocorrer uma diminuição da densidade da óssea (REID , 2000; HANLEY et al., 2000; SELBY et al., 2000; JOY et al., 2000; CRANNEY et al., 2000; NEGRI et al., 1999; SAMBROOK, 2000)

Atualmente, a corticoterapia também é usada em pacientes que realizaram transplantes de órgãos e em pós-operatórios em geral afim de que haja um incremento da sobrevida destes pacientes. Porém, segundo Negri et al., (1999), a ciclosporina associada a altas doses de corticóides, produz efeitos deletérios no tecido ósseo e metabolismo mineral, predispondo os indivíduos a fraturas, principalmente das vértebras. Estes autores observaram ainda que muitos pacientes aguardando transplante pulmonar têm osteoporose devido ao uso prolongado de corticóides em função de sua patologia crônica.

Joy et al. (2000), observaram que paciente transplantado ou portador de glomerulonefrite que faz uso da corticoterapia pode ter um grau de osteoporose acentuado. Estes autores sugerem que tais pacientes sejam avaliados e clinicados por uma equipe multidisciplinar, para que venha se beneficiar de todos os recursos, que cada profissional na sua área possa contribuir para minimizar a diminuição da massa óssea devido ao uso de corticóides por tempo prolongado. O objetivo é diminuir o risco de fraturas e 
de deixar seqüelas.

Stafford et al., (2000), investigaram a prevalência de osteoporose em um grupo de 50 homens com artrite reumatóide, sendo estes com idade média de 50 anos e média de manifestação da doença de 20 anos. Entre estes, 14 pacientes não foram tratados com corticóides e os 36 remanescentes receberam altas doses de corticóides por tempo prolongado. Estes autores observaram que a coluna vertebral e o colo femural apresentaram uma redução da densidade mineral óssea em 38 e $71 \%$ respectivamente, levando estes autores a concluírem que os pacientes que fizeram tratamento com corticóides em função da artrite reumatóide tiveram uma perda significante da densidade mineral óssea da coluna vertebral e colo femural.

Adachi, (2001), observou que fraturas da coluna e quadril têm ocorrido numa média de 30 a $50 \%$ de pacientes que fazem uso de corticosteróides por tempo prolongado e que as fraturas da coluna são as mais freqüentes.

Selby et al., (2000), compararam a relação entre a densidade mineral óssea e a fratura vertebral em pacientes que usaram corticosteróides e em pacientes que nunca usaram essa terapia.

Foram analisadas as radiografias tóraco-lombares lateral de 452 pacientes, sendo que 391 eram do sexo feminino. Do total de radiografias dos pacientes analisados, foram observados 82 que faziam uso da corticoterapia, sendo 63 do sexo feminino. Foi observado que não houve nenhuma diferença significativa da densidade mineral óssea dos pacientes sob tratamento corticoterápico quando comparado com ocorrência de osteoporose por outras causas. Foram observadas também que as fraturas vertebrais estavam presentes em $53 \%$ dos pacientes submetidos a corticoterapia comparado com $35 \%$ dos que não tiveram nenhum tratamento com corticóide.

Sambrook et al., (2000) observaram que em função dos corticóides serem extensamente usados nos tratamentos de doenças 
inflamatórias crônicas e da perda de massa óssea acontecer mais rapidamente entre 12 e 24 meses após o início do tratamento com alta dose de corticóide, a administração de cálcio, de bisfosfonatos e de vitamina $D$ nos pacientes antes e durante o tratamento é recomendável, podendo ter seu uso continuado até 2 anos após o término do tratamento com corticóides, afim de se evitar ou diminuir a perda de massa óssea.

Os corticosteróides são usados sistematicamente nas várias especialidades médicas por ser um fármaco potente como anti-inflamatório, tendo sua aplicação nos casos de pós-operatório em geral, patologias inflamatórias crônicas e transplantes. Há várias pesquisas científicas que relatam os efeitos maléficos da corticoterapia no tecido ósseo. Entre eles a diminuição da densidade óssea é um dos efeitos mais citados, porém, nenhum estudo foi encontrado relatando as alterações das propriedades mecânicas dos ossos longos analisando como uma estrutura através de ensaios mecânicos de flexão em três pontos e dos tecidos ósseos corticais e trabeculares, na forma de corpo de prova, sendo analisado como material, através de ensaios de flexão em três pontos e de compressão. 


\section{0 - OBJETIVOS}

A proposta desta pesquisa foi avaliar as possíveis alterações das propriedades mecânicas dos ossos de coelhas quando submetidas à administração de altas doses por tempo prolongado de corticosteróide. Para isto, foram realizados dois tipos de análises.

1- Análise estrutural dos ossos longos (tíbias e fêmures), através de ensaios de flexão em três pontos.

2- Análise do osso como material, através de CDPs obtidos da região central dos fêmures (tecido ósseo cortical) e de CDPs obtidos das vértebras (L5) (tecido ósseo trabecular). Para os CDPs obtidos dos fêmures foram realizadas os ensaios de flexão em três pontos, e para os CDPs obtidos das vértebras foram realizadas os ensaios de compressão. 


\section{0- MATERIAIS E MÉTODOS}

\section{1- Animais}

Para este estudo foram utilizadas 39 coelhas albinas adultas da raça Nova Zelândia, com peso corporal médio de 3664 gramas, fornecidas pelo Biotério Central do Campus de Ribeirão Preto da Universidade de São Paulo (USP). Os animais foram mantidos em gaiolas de contenção de polietileno, com livre acesso a água e ração, ficando expostos a ciclos de 12 horas claro e 12 horas escuro.

Inicialmente, os primeiros 24 animais do estudo foram transferido para o Biotério da Clínica Médica da Faculdade de Medicina de Ribeirão Preto (FMRP/USP) para serem submetidos ao tratamento proposto, devido à ausência de gaiolas suficientes para alojamento adequado dos animais no Biotério do Laboratório de Bioengenharia. Os demais animais, um total de 15 , foram tratados e mantidos no Biotério do Laboratório de Bioengenharia.

Os animais foram alimentados com ração padrão normal e água "ad libitum". 


\section{2 - Grupos de Animais}

Os animais foram divididos em quatro grupos, sendo 2 grupos para realizar a análise estrutural e 2 grupos para analisar o tecido ósseo através de corpos de prova.

Para análise estrutural dos ossos longos foram divididos em dois grupos, o primeiro grupo controle 1 (GC1) foi composto por 12 coelhas, nas quais foram administradas soluções salina. $O$ grupo experimental (GE1) foi composto por 12 coelhas, que foram submetidas ao protocolo de tratamento utilizando o corticóide. As tíbias e os fêmures do lado direito destes dois grupos foram avaliados por ensaio mecânico de flexão em 3 pontos, compondo os subgrupos GC1T(controle) e GE1T(experimental) para as tíbias e GC1F(controle) e GE1F(experimental) para os fêmures, Quadro 01.

QUADRO 1 - Legenda dos subgrupos da análise estrutural

\begin{tabular}{|c|c|c|}
\cline { 2 - 3 } \multicolumn{1}{c|}{} & Grupo controle & Grupo experimental \\
\hline Tíbia & GC1T & GE1T \\
\hline Fêmur & GC1F & GE1F \\
\hline
\end{tabular}

Para análise do osso como material os animais foram divididos em outros dois subgrupos, o grupo controle 2 (GC2) composto por 5 coelhas e o grupo experimental 2 (GE2) composto por 10 coelhas. Um animal de cada grupo foi a óbito por causa indeterminada durante o tratamento. Os animais do grupo GC2 foram submetidos ao mesmo processo de administração de solução salina do grupo GC1.

Os animais do grupo GE2 foram submetidos ao protocolo de tratamento idêntico ao do grupo GE1. Nestes dois grupos, a análise foi realizada através de ensaios mecânicos de compressão e de flexão em 3 pontos em corpos de prova (CDPs) de vértebras (L5) e fêmures direitos 
respectivamente, compondo os subgrupos GC2F(controle) e GE2F(experimental) para os CDPs obtidos dos fêmures e GC2V(controle) e GE2V(experimental) para os CDPs das vértebras (Quadro 02).

QUADRO 2 - Legenda dos subgrupos da análise do osso como material

\begin{tabular}{|c|c|c|}
\cline { 2 - 3 } \multicolumn{1}{c|}{} & Grupo Controle & Grupo Experimental \\
\hline Fêmur & GC2F & GE2F \\
\hline Vértebra & GC2V & GE2V \\
\hline
\end{tabular}

\section{3- Protocolo de Administração do Medicamento}

Em todos os grupos experimentais foram administradas, durante 21 dias, no período da manhã, injeções subcutâneas de metilprednisolona (Solumedro ${ }^{\circledR}$ - Pharmacia-Up-John S.A.-Puurs), diluída em solução salina, nas doses de $2 \mathrm{mg} / \mathrm{kg} / \mathrm{dia}$, sendo realizadas correções destas dosagens æ̀ segundas, quartas e sextas feiras, levando -se em conta as alterações de peso corporal dos animais.

Com o objetivo de verificar se a medicação causava algum tipo de alterações no consumo alimentar, a quantidade de alimento consumido foi medida a cada dois dias, onde se pesava a alimentação do comedouro quando o mesmo era cheio e após dois dias antes de ser completado.

Um dia após o tratamento, todos animais foram submetidas a eutanásia. 


\section{4 - Preparo das Peças}

Todos os animais dos quatro grupos, foram eutanasiados, utilizando-se doses letais do anestésico Thiopental ${ }^{\circledR}$ (1 grama diluída em 40 $\mathrm{ml}$ de soro fisiológico), de modo intravenoso até que ocorresse parada cardíaca. Posteriormente a confirmação do óbito, foi retirada toda pele do animal, como forma de auxiliar na visualização, localização, bem como, extração e dissecação dos fêmures e tíbias direitas, assim como as vértebras (L5) de cada coelha.

Após dissecadas e limpas todo o material coletado foram identificados individualmente. Durante o processo de dissecação dos ossos, os mesmos foram mantidos a temperatura ambiente e constantemente hidratados com soro fisiológico.

Nas tíbias e fêmures dos grupos GC1 e GE1, foram mensurados os comprimentos longitudinais, utilizando um paquímetro da marca Mitutoyo ${ }^{\circledR}$. Para o fêmur a medida do comprimento longitudinal foi realizada, da cabeça do fêmur até o côndilo medial. Para a tíbia, padronizouse medir do ápice da cabeça da fíbula até a extremidade do côndilo medial. O valor de cada comprimento longitudinal foi dividido por 2 , no qual foi localizado a região mais central de cada osso. Nesta região foi medida o comprimento circunferencial das tíbias e fêmures. Esta medida foi obtida com auxílio de um barbante envolvendo toda a sua circunferência.

Após a realização das medidas dos comprimentos, os ossos foram pesados individualmente utilizando uma balança digital com precisão de $0,01 \mathrm{~g}$ da marca Precision- $\operatorname{Pr} 500^{\circledR}$. Posteriormente, os ossos foram envolvidos por gazes embebidas com soro fisiológico e guardado em freezer á $-20^{\circ} \mathrm{C}$ até as vésperas dos dias de realização dos ensaios mecânicos. Para realização dos ensaios mecânicos, os ossos foram retirados com no mínimo 12 horas de antecedência e colocados em geladeira. Nos dias dos ensaios, os ossos, foram retirados pelo menos 01 hora antes para que 
entrassem em equilíbrio térmico com 0 ambiente. Todo esse processo ocorreu tomando-se o cuidado de sempre estar hidratando os ossos com soro fisiológico.

\subsubsection{Confecção dos Corpos de Prova (CDPs)}

\subsubsection{Fêmur}

Para a confecção dos corpos de prova dos subgrupos GC2F e GE2F, também foram mensurados o comprimento longitudinal dos fêmures utilizando o mesmo procedimento de medida realizada para os subgrupos GC1F e GE1F.

Após a localização da região central anterior de cada fêmur, foi realizada as marcações e o posicionamento para a obtenção do CDP. As demarcações utilizadas para a retirada dos corpos de prova dos fêmures estão ilustradas na figura 01.

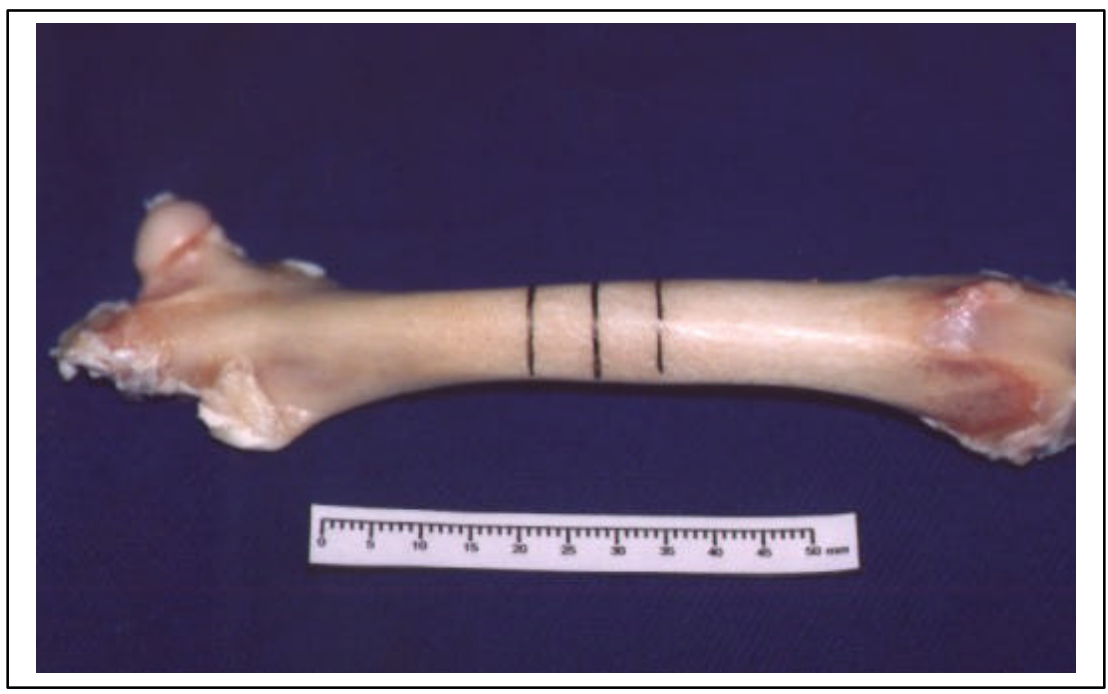

FIGURA 01 - Fêmur marcado para obtenção do CDP. 
Em seguida, o fêmur foi serrado na sua marcação proximal, e demarcado com tinta nesta extremidade, permitindo assim que o segmento restante do osso pudesse ser fixado no acessório da máquina de serrar modelo ISOMET $1000^{\circledR}$ da marca BUEHLER (serra diamantada), para realizar os cortes de cada do corpo de prova, além de servir como ponto de identificação da região proximal. Seguindo estes procedimentos foi padronizado para todos os corpos de prova um comprimento de $12 \mathrm{~mm}$ e largura de $2 \mathrm{~mm}$ (Figura 02).

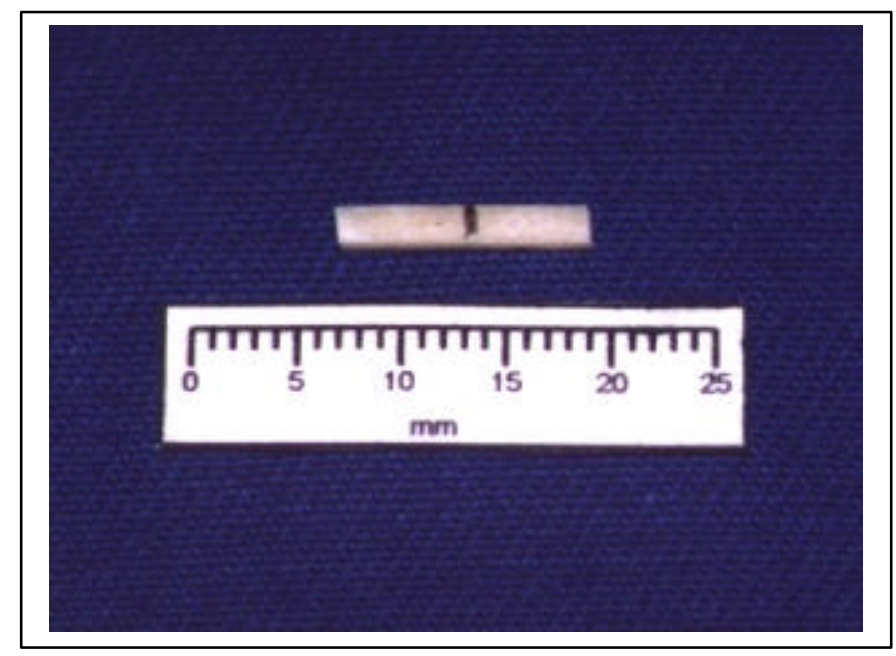

FIGURA 02 - CDP obtido do fêmur

\subsubsection{2- Vértebras}

Após a extração e dissecação das vértebras dos animais foram adotados alguns procedimentos para adequada confecção dos corpos de prova. Todo o tecido cartilaginoso presente nas articulações foi extraído com auxílio de uma lixa d'água número 400.

Em seguida a vértebra foi fixada em um acessório e fixada na máquina de serrar ISOMET $1000 \AA$, para que se fosse realizado o primeiro corte. Foi padronizado inicialmente a retirada de $5 \mathrm{~mm}$ da região distal de 
todas as vértebras, eliminando qualquer possibilidade de se obter um corpo de prova com resquícios de tecido cartilaginoso (Figura 03). Concluído este procedimento, a vértebra então foi novamente fixada ao acessório da máquina para a retirada de um novo segmento ósseo de $3 \mathrm{~mm}$ de espessura da parte distal da vértebra, obtendo-se assim o corpo de prova que foi ensaiado. A figura 04 apresenta um exemplo da vértebra e de um CDP.

$O$ procedimento de conservação das vértebras foi o mesmo utilizado para os fêmures.

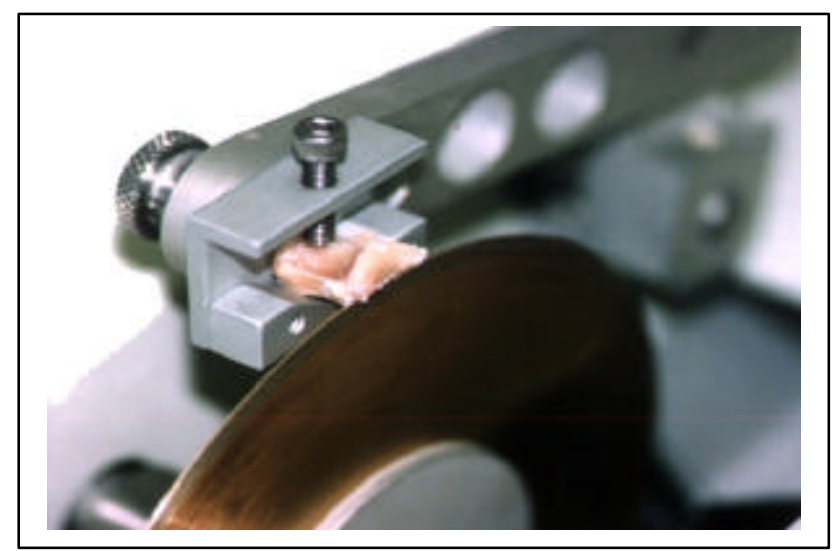

FIGURA 03 - Vértebra posicionada para o primeiro corte de $5 \mathrm{~mm}$

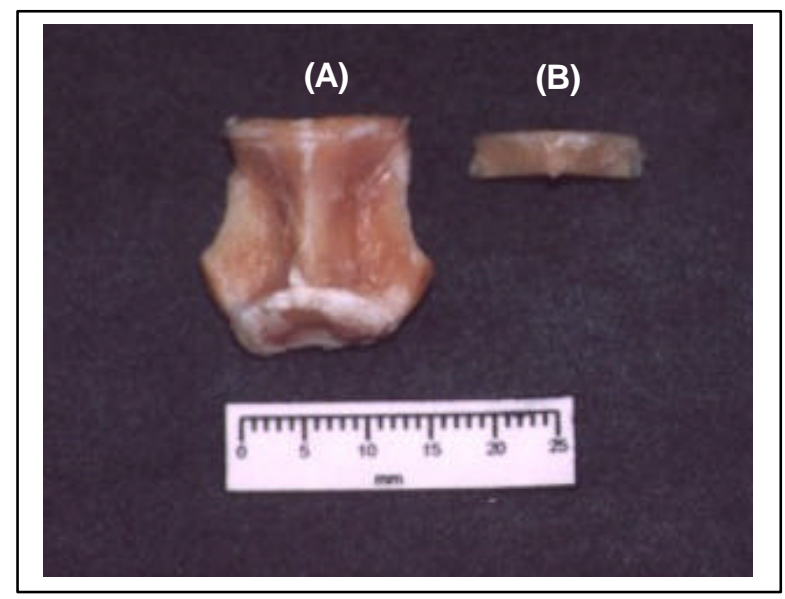

FIGURA 04 - (A) Vértebra e (B) CDP obtido da vértebra 


\subsection{Ensaios Mecânicos de Flexão das tíbias e fêmures}

Os ensaios mecânicos de flexão em três pontos das tíbias e dos fêmures dos grupos GC1 e GE1 foram realizados na Máquina Universal de Ensaio do Laboratório de Bioengenharia da FMRP - USP.

Os ensaios foram padronizados a partir da realização de estudos pilotos, no qual ficaram estabelecidos: a aplicação de uma pré-carga de 2,5 N, com um tempo de acomodação de 30 segundos e a velocidade de aplicação de carga de $0,5 \mathrm{~mm} / \mathrm{min}$. A carga foi aplicada na região central do osso, através de um acessório acoplado a célula de carga.

A célula de carga utilizada neste estudo foi da marca $\operatorname{KRATOS} \circledast$ com capacidade de suporte de carga de $50 \mathrm{Kgf}$, conectada a uma ponte de extensiometria Sodmex®.

Um relógio comparador Mitutoyo ${ }^{\circledR}$, com precisão de $0,01 \mathrm{~mm}$ foi utilizado para a coleta dos intervalos de deflexão durante todo ensaio mecânico.

Os valores de deflexão foram medidos a cada $0,05 \mathrm{~mm}$, sendo realizada simultaneamente com uma leitura do valor da carga aplicada na ponte de extensiometria.

As medidas de deflexão e carga aplicada foram colhidas até o momento da ruptura óssea ou até que os valores começassem a diminuir indicando que o osso atingiu sua capacidade máxima de resistir a carga aplicada. Quando os valores começavam a decrescer, foram padronizados a adoção de no máximo até 5 medidas e se ainda assim o osso não tivesse rompido o ensaio era finalizado.

A figura 05 apresenta uma tíbia bi-apoiada e posicionada sobre o acessório e um outro acessório conectado a célula de carga. A figura apresenta ainda um relógio comparador utilizado nas medidas das deflexões dos ossos. 


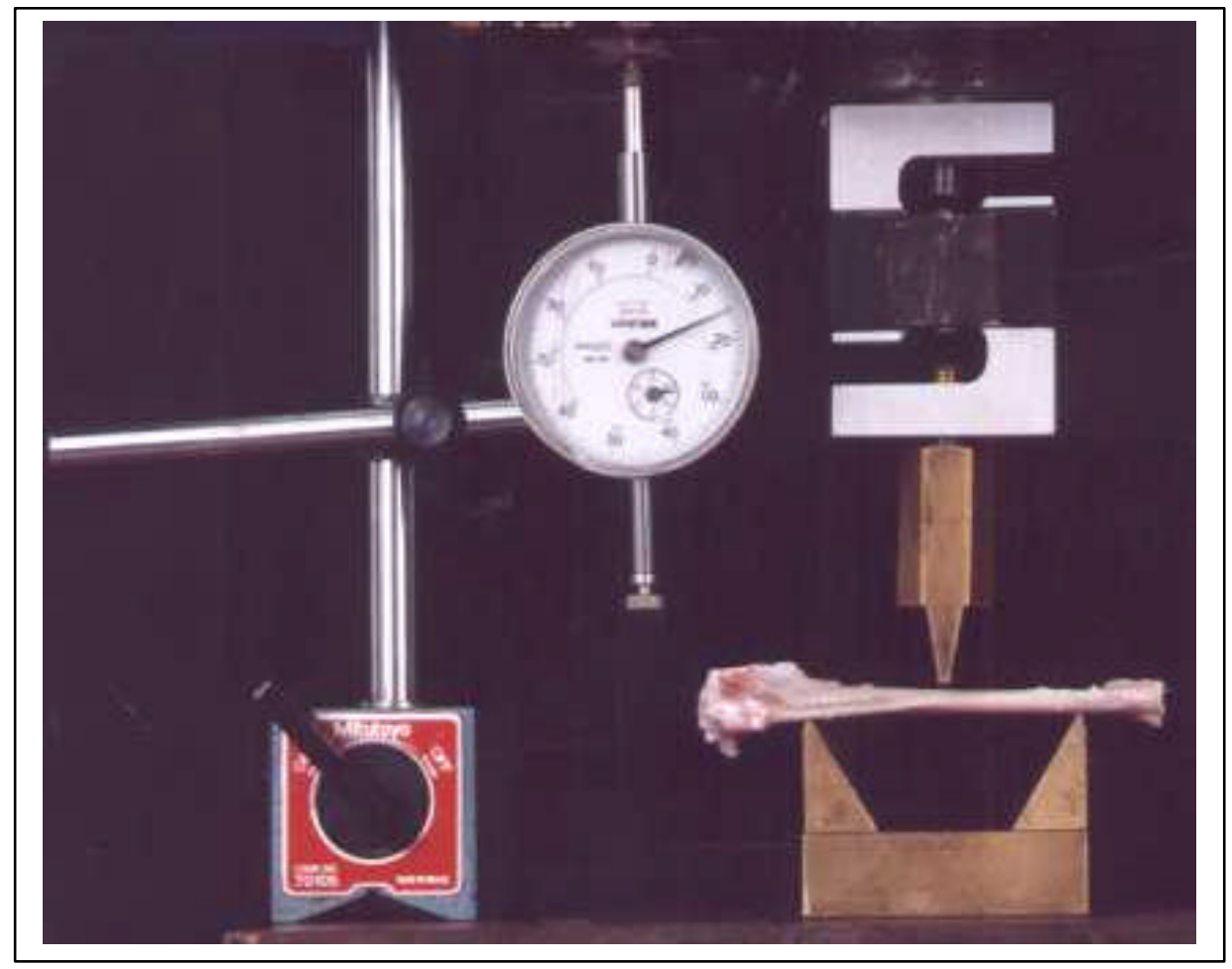

FIGURA 05 - Tíbia posicionada para realização do ensaio de flexão.

Para a realização dos ensaios de flexão em três pontos foi padronizada uma distância de $60 \mathrm{~mm}$ entre os apoios.

Os ossos foram sempre posicionados sobre o acessório, de modo que o sentido de aplicação da carga fosse no sentido ântero-posterior. A figura 06-A apresenta um fêmur e a figura 06-B apresenta uma tíbia.

Os dois ossos estão bi-apoiados sobre o acessório para a realização dos ensaios. 


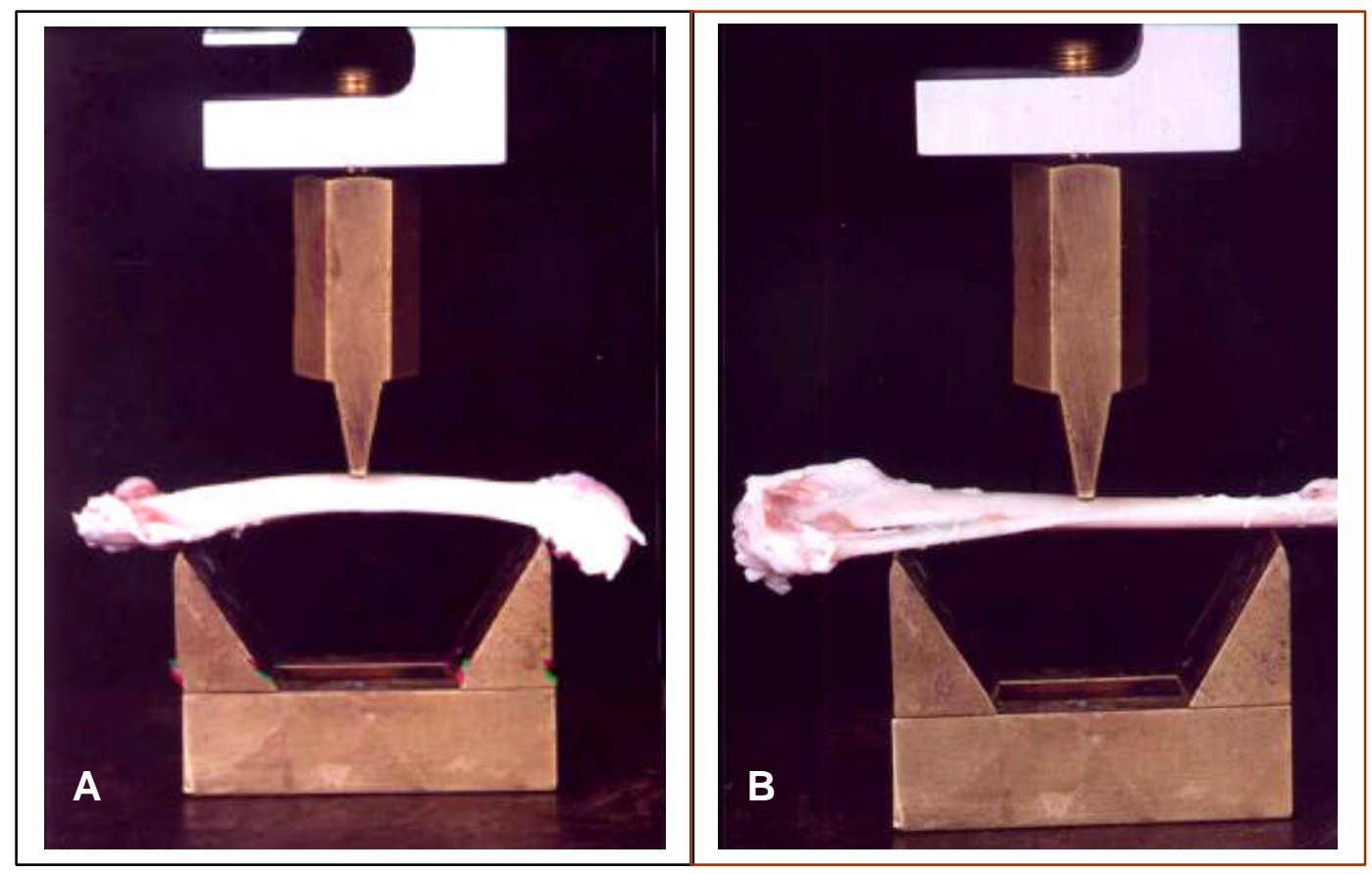

FIGURA 06 - (A) Fêmur e (B) Tíbia bi-apoiados sobre o acessório.

\subsection{Ensaios Mecânicos de Flexão em CDPs de fêmures}

Os ensaios de flexão em três pontos dos CDPs obtidos dos fêmures, foram realizados na Máquina EMIC ${ }^{\circledR}$ do Laboratório de Bioengenharia da FMRP - USP.

Para realização dos ensaios de flexão foi utilizado um acessório idêntico ao utilizado nos ensaios para análise estrutural das tíbias e fêmures, mas com dimensões menores. O corpo de prova foi apoiado em dois pontos mais extremos e um outro acessório ajustado na sua parte central para aplicação da carga. A figura 07 apresenta um CDP obtido da região central anterior do fêmur posicionado sobre o acessório $(A)$ e um outro acessório (B) conectado a célula de carga. 


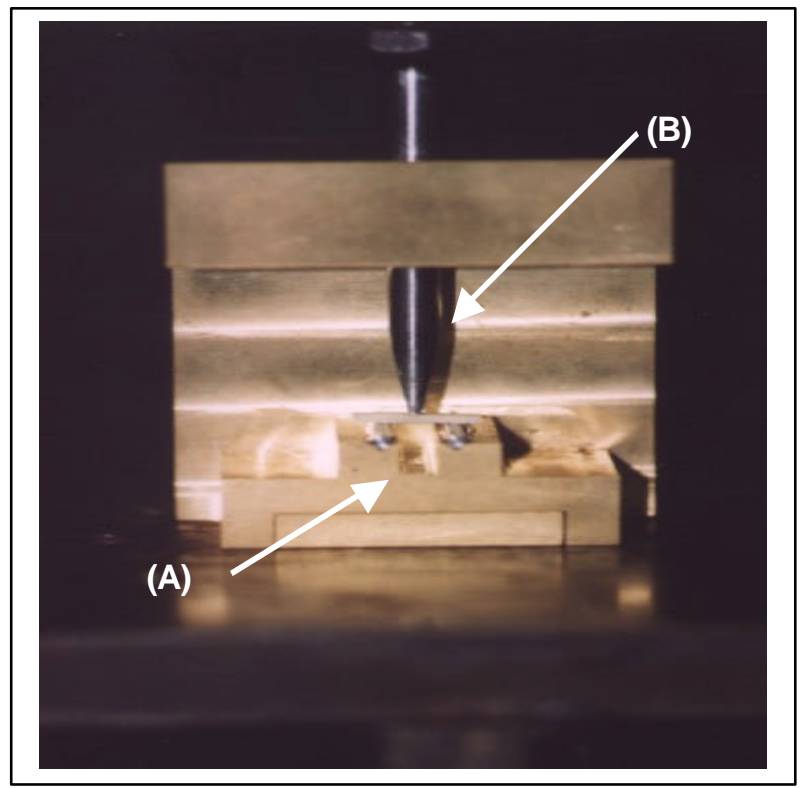

FIGURA 07 - (A) CDP de fêmur bi - apoiado sobre o acessório e (B) acessório para aplicação da carga.

Para a realização dos ensaios de flexão em três pontos dos CDPs foi padronizada uma distância de $7 \mathrm{~mm}$ entre os apoios. Os corpos de prova foram sempre posicionados sobre o acessório, de modo que o sentido de aplicação da carga fosse na região do endósteo, ficando a parte do periósteo para baixo.

Padronizou-se utilizar em todos os ensaios uma pré-carga de $0,200 \mathrm{kgf}$ e um tempo de acomodação de 30 segundos. A velocidade de aplicação de carga utilizada foi de $0,1 \mathrm{~mm} / \mathrm{min}$.

A carga foi aplicada sobre o corpo de prova, até que houvesse a ruptura do mesmo, e durante todo o ensaio a máquina universal registrou os valores de tensão máxima, tensão na ruptura e força máxima. Foi ainda confeccionado um gráfico da força aplicada(Kgf) versus deflexão $(\mathrm{mm})$ para cada corpo de prova ensaiado. 


\section{7 - Ensaios Mecânicos de Compressão em Vértebra}

Para a realização dos ensaios mecânicos de compressão dos CDPs obtidos das vértebras, foi confeccionado um acessório especial com diâmetro de $2 \mathrm{~mm}$ em sua extremidade que foi acoplado na célula de carga com a finalidade de comprimir a região central do corpo de prova vertebral, composto especificamente por osso trabecular (figura 08). Este ensaio foi baseado nos trabalhos realizados por Hogan et al., 2000.

O corpo de prova foi posicionado com a parte mais larga (distal) apoiada sobre a base da máquina de ensaio. Foi utilizada uma précarga de $0,5 \mathrm{Kgf}$ (aproximadamente $5 \mathrm{~N}$ ), um tempo de acomodação de 30 segundos e uma velocidade de aplicação da carga de $0,1 \mathrm{~mm}$ por minuto. $O$ limite máximo para a deformação foi estabelecido em $0,4 \mathrm{~mm}$ para todos os ensaios nestes tipos de CDPs.

Durante o ensaio mecânico a máquina universal de ensaio registrou a força e a tensão máxima aplicada sobre os CDPs. Foram registrados também os gráficos força aplicada versus deformação.

A figura a seguir ilustra a utilização do acessório especial e o CDP obtido da vértebra.

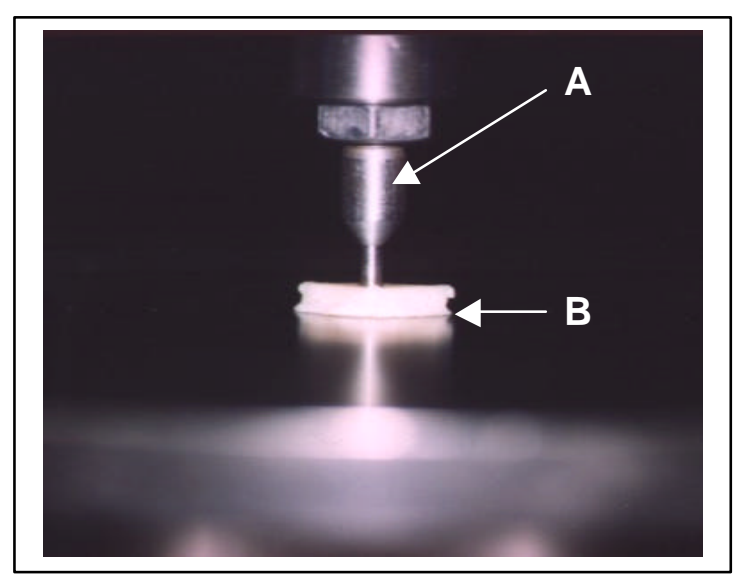

FIGURA 08 - (A) Acessório especial e (B) CDP obtido da vértebra 


\section{8 - Gráficos Carga versus Deflexão}

Os valores das deflexões e das cargas obtidos nos ensaios mecânicos foram utilizados para confecção dos gráficos carga aplicada versus deflexão utilizando-se do programa Microsoft Excel $98^{\circledR}$. Com a confecção destes gráficos foi possível determinar as propriedades mecânicas avaliadas neste estudo. Os gráficos foram utilizados para analisar os subgrupos GC1T, GE1T, GC1F e GE1F.

Em cada gráfico, a carga foi representada no eixo das ordenadas e a deflexão no eixo das abscissas, e através deles foram calculadas as propriedades mecânicas resultantes do ensaio. A figura 09 apresenta um exemplo de gráfico da carga aplicada em função da deflexão

Este gráfico servirá para demonstrar como foram realizados os cálculos e obtenção das propriedades mecânicas dos ossos. O gráfico apresenta 0 limite de proporcionalidade (LP), a reta que representa a inclinação da curva $(\theta)$, e o triângulo formado pela união dos pontos no início do ensaio e LP. A letra $\underline{h}$ representa a altura, $\underline{b}$ a base e $\underline{a}$ área do referido triângulo.

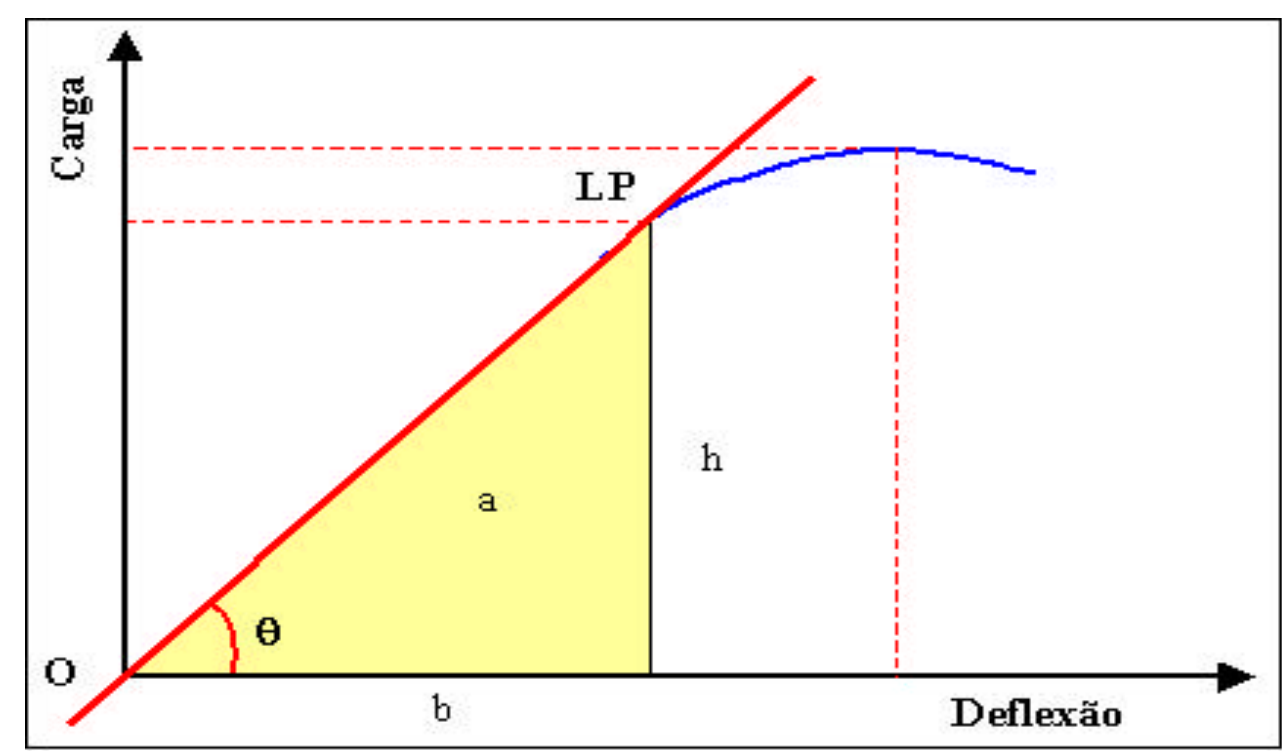

FIGURA 09 - Gráfico carga x deflexão ilustrando o limite de proporcionalidade (LP), a reta que representa a inclinação da curva $(\theta)$, e o triângulo formado pela união dos pontos de início do ensaio e LP. A letra $\underline{h}$ representa a altura, $\underline{b}$ a base $\mathrm{e} \underline{\mathrm{a}}$ área do referido triângulo. 


\subsection{1 - Carga no Limite de Proporcionalidade}

A carga no limite de proporcionalidade (LP) foi identificada como sendo o último ponto que se encontrava no segmento linear da curva carga x deflexão. Para obtenção, foi traçada uma linha reta a partir do início da curva, seguindo sua inclinação, identificando o último ponto inserido nesta reta.

\subsubsection{Deformação no Limite de}

\section{Proporcionalidade}

A partir do ponto identificado como limite de proporcionalidade foi traçada uma linha em direção ao eixo das abscissas e registrada a deflexão correspondente, que é a última deformação observada na fase elástica do ensaio.

\subsection{3 - Rigidez}

A rigidez é dada pela inclinação da reta, que representa a fase elástica do material, no gráfico (carga aplicada $x$ deflexão), por meio do cálculo da tangente do ângulo formado pela inclinação da reta e uma linha traçada horizontalmente, a partir do ponto de início do gráfico que representa o início do ensaio. Traçando uma linha vertical a partir do ponto da curva identificado como limite de proporcionalidade, forma-se um triângulo. $\mathrm{O}$ cateto oposto ao ângulo $\theta$ ) representa o valor da carga aplicada (h) e 0 cateto adjacente o valor da deflexão (b) (Figura 09).

\subsection{4 - Resiliência}

A resiliência do material ensaiado também conhecida por energia absorvida na fase elástica, é calculada pela área do triângulo retângulo representada na figura 09. 


\subsection{5 - Carga e Deflexão Máxima}

Foram registrados também, para efeito de comparações, os maiores valores das cargas aplicadas máxima e das deflexões de cada osso ensaiado.

\section{9 - Tensão Máxima}

Esta propriedade foi obtida diretamente do software que tem interface com a máquina universal de ensaio EMIC ${ }^{\circledR}$.

Para a realização dos ensaios de flexão em três pontos dos CDPs obtidos da região central anterior dos fêmures, foram informadas ao software da máquina, as medidas de espessura e a largura do CDPs, bem como, o comprimento do vão livre onde estes foram apoiados. A partir destes dados, automaticamente foram calculadas as áreas e momentos de inércias, parâmetros estes indispensáveis para os cálculos das tensões máximas.

Para os ensaios mecânicos de compressão dos CDPs de vértebras, também foi informado ao software o valor da área da secção transversal do acessório utilizado para compressão dos CDPs, onde através deste valor foi calculado as tensões máximas.

\subsection{0 - Análise Estatística}

Os resultados obtidos foram expressos na forma de média aritmética com seus respectivos desvios padrão. Foi utilizado o teste $T$ de Student não pareado com nível de significância estabelecido em 5\% Toda a análise estatística dos resultados encontrados foi processada no programa Graph Pad-Instat ${ }^{\circledR}$ v.3.0 


\section{0 - RESULTADOS}

Os resultados encontrados neste estudo foram divididos em duas partes, onde primeiramente foi realizada toda a avaliação de dados antropométricos e de consumo alimentar colhidos durante todo experimento. Posteriormente, serão apresentadas as propriedades mecânicas relativas as análises: estrutural das tíbias e fêmures e do osso como material utilizando os fêmures e vértebras (L5).

\section{1 - Peso dos Animais}

Os animais dos grupos controles (GC1 e GC2) tiveram peso médio inicial de $(3686 \pm 130) \mathrm{g}$ e após 21 dias de tratamento com solução salina, os grupos apresentaram um peso médio de $(3826 \pm 84,15) \mathrm{g}$

Os animais dos grupos experimentais (GE1 e GE2) apresentaram um peso médio inicial de $(3642 \pm 147) \mathrm{g}$ e um peso médio final de (3364 \pm 128$) g$ após 21 dias de tratamento a base de corticóide.

Realizando-se a comparação dos valores dos pesos dos animais no início do tratamento entre os grupos (controle e experimental) não foi observada diferença estatística significativa $(p>0,05)$. No entanto, na comparação dos pesos corporais dos animais desses grupos após 21 dias 
de tratamento, foi observada uma diferença estatística significativa entre os dois grupos estudados $(p<0,05)$.

A figura 10 representa os valores médios do peso inicial e final dos animais de todos os grupos controle e experimental.

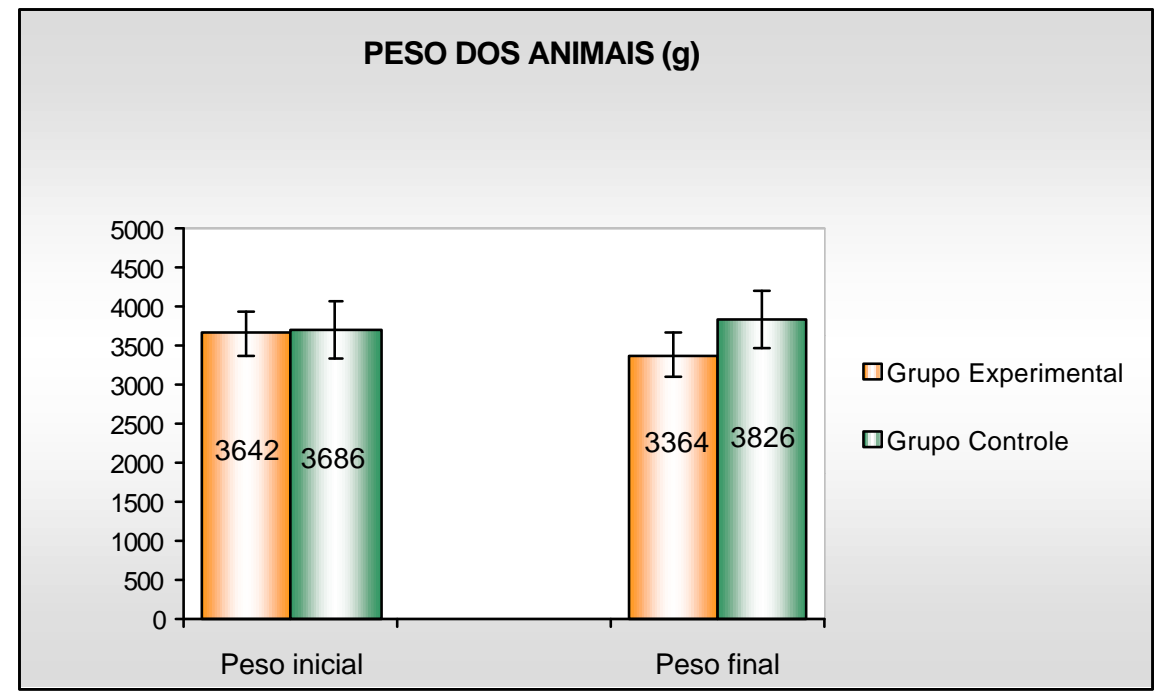

FIGURA 10 - Representa os valores médios do peso inicial e final dos animais dos grupos experimental e controle.

\section{2 - Consumo Alimentar}

O peso médio de consumo diário de ração para o grupo controle foi de $(138,4 \pm 28,3) \mathrm{g}$ e para o grupo experimental o consumo foi de $(149,1 \pm 25,6) \mathrm{g}$. A figura 11 apresenta graficamente os valores médios de consumo alimentar entre os grupos de animais controles e experimentais. Comparando as médias do consumo alimentar entre o grupo de coelhas tratadas com corticóide e o grupo de coelhas tratadas com solução salina, verificou-se que não houve diferença estatística significativa entre eles $(p>0,05)$. 
A figura 11 representa os valores médios de consumo alimentar entre os grupos ao término do experimento.

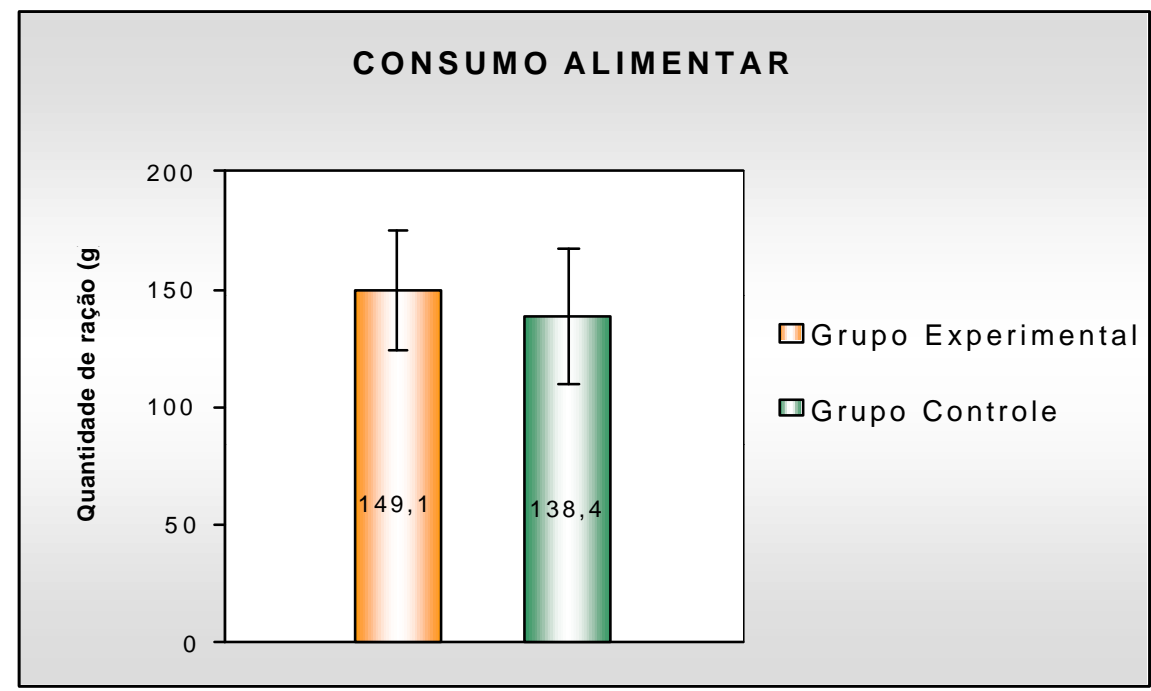

FIGURA 11 - Valores médios de consumo alimentar entre os grupos experimental e controle.

\section{3 - Medidas Antropométricas e Propriedades Mecânicas das Tíbias como Estrutura}

Além do peso médio e dos desvios padrão das tíbias de cada subgrupo, serão também apresentados os valores médios e desvios padrões também do comprimento longitudinal e do comprimento circunferencial da região central da diáfise de cada osso. Posteriormente, serão apresentados as médias e desvios padrão das propriedades mecânicas e as suas comparações. 


\subsection{1 - Peso da tíbia}

Os pesos médios das tíbias dos subgrupos experimentais (GE1T) e do subgrupo controles (GC1T) foram de $(10,6 \pm 1,1) \mathrm{g}$ e $(11,2 \pm$ 1,9)g, respectivamente. A figura 12 apresenta estes valores representados graficamente. Comparando-se os pesos dos dois grupos, não foi observada diferença estatística significativa entre eles $(p=0,36)$.

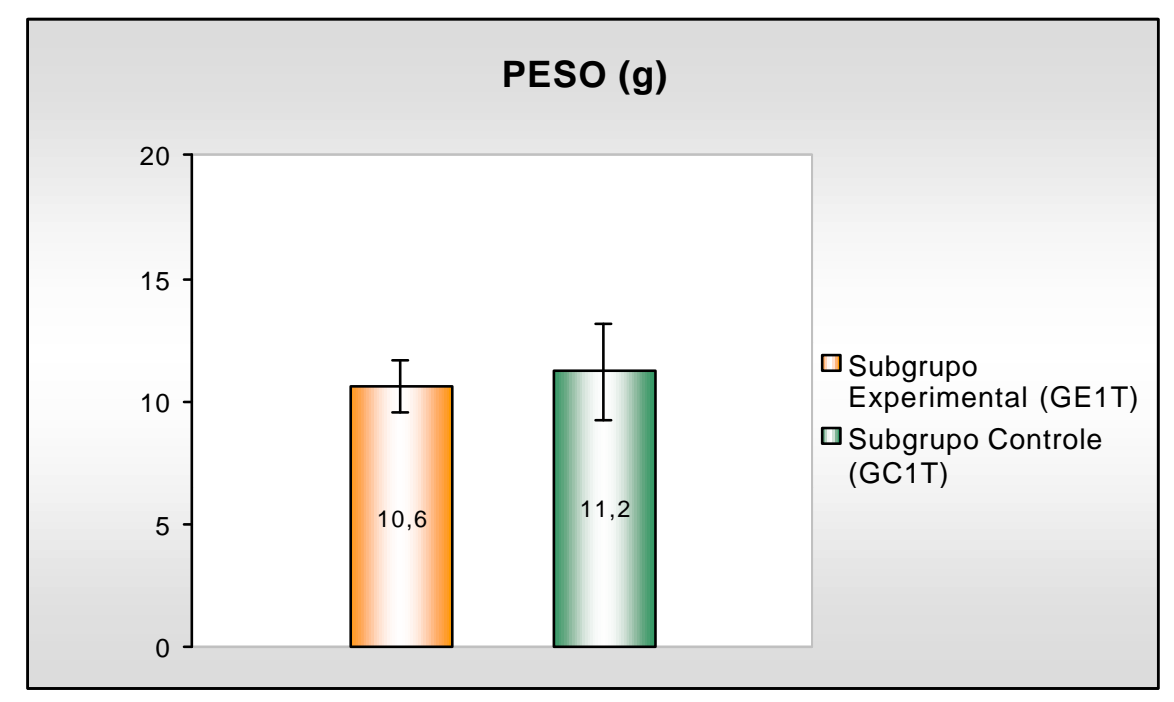

FIGURA 12 - Valores médios dos pesos das tíbias do subgrupo experimental (GE1T) e controle (GC1T).

\subsection{2 - Comprimento Longitudinal}

O valor médio do comprimento das tíbias do subgrupo experimental (GE1T) foi de $(107,1 \pm 3,7) \mathrm{mm}$ e o valor médio das tíbias do subgrupo controle $(\mathrm{GC1T})$ foi de $(110,3 \pm 3,4) \mathrm{mm}$. $\mathrm{Na}$ análise estatística realizada entre o comprimento das tíbias dos dois subgrupos, não foi observada diferença significante entre si $(p=0,07)$. 
A figura 13 demonstrada a seguir apresenta estes valores médios do comprimento longitudinal graficamente.

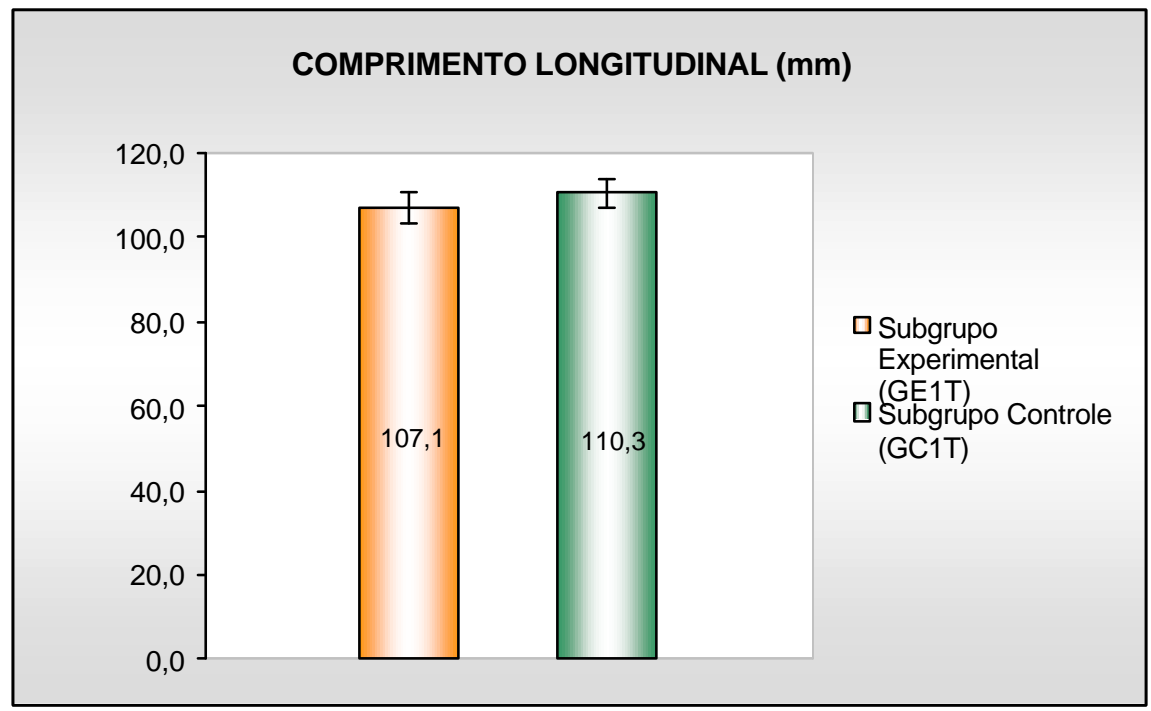

FIGURA 13 - Valores médios dos comprimentos longitudinais das tíbias do subgrupo experimental (GE1T) e controle (GC1T).

\subsection{3 - Comprimento Circunferencial}

O valor médio do comprimento circunferencial obtidos da região central da diáfise das tíbias do subgrupo experimental (GE1T) foi de $(29,0 \pm 2,7) \mathrm{mm}$ e das tíbias do subgrupo controle (GC1T) foi de $(30,0 \pm 3,5)$ $\mathrm{mm}$. Na realização da análise estatística não foi observados diferença estatística significativa entre os subgrupos experimental e controle $(p=0,44)$. 
O gráfico das médias encontradas para o comprimento circunferencial está demonstrado a seguir na figura 14 .

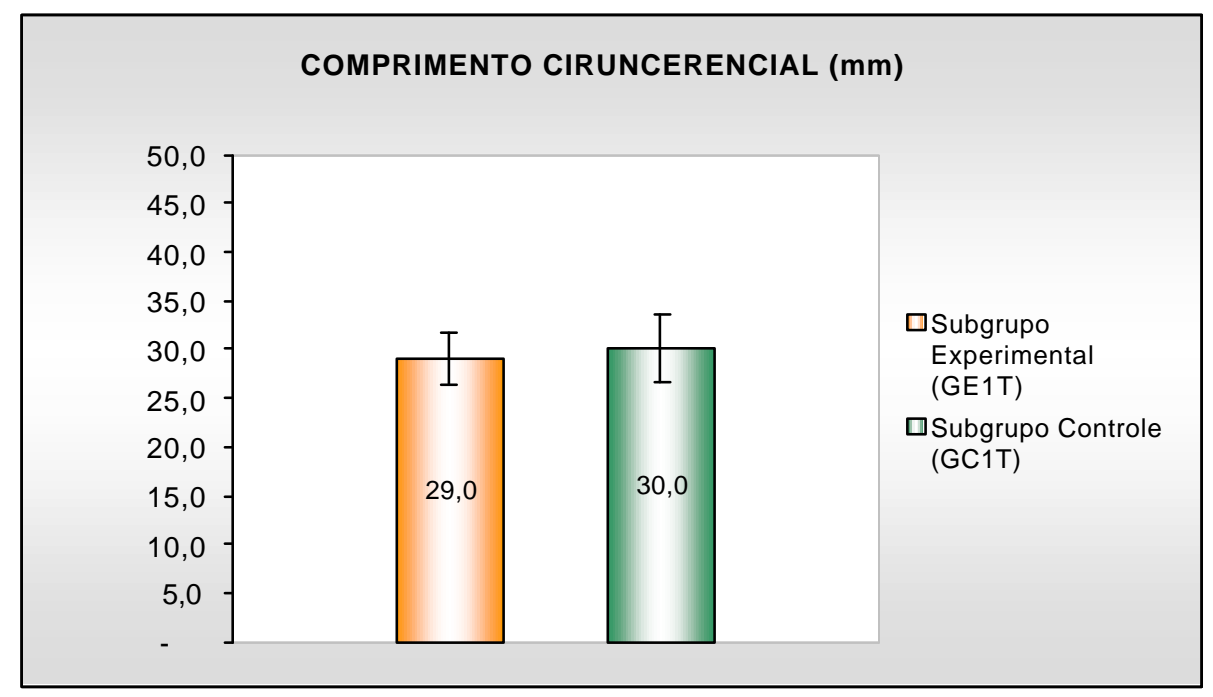

FIGURA 14 - Valores médios dos comprimentos circunferenciais das tíbias do subgrupo experimental (GE1T) e controle (GC1T) obtidas da região central da diáfise óssea.

\subsection{4 - Gráficos Carga versus Deflexão}

As curvas carga versus deflexão para cada animal foram obtidas através dos ensaios mecânicos de flexão em três pontos, e estão expressas a seguir nas figura 15 e 16.

A figura 15 demonstra graficamente os ensaios mecânicos realizados no subgrupo experimental das tíbias de 12 coelhas tratadas a base de corticóides (GE1T), e a figura 16 apresenta os gráficos dos ensaios mecânicos realizado no subgrupo controle das 12 tíbias de coelhas tratadas com solução salina (GC1T). 


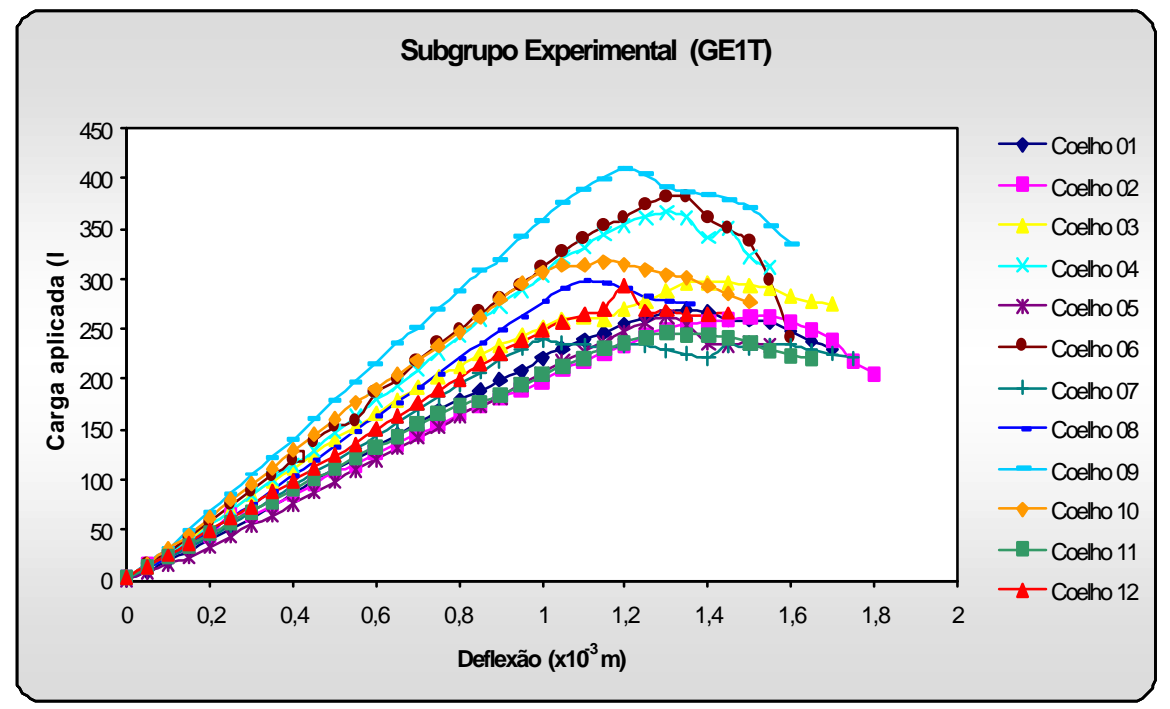

FIGURA 15 - Gráfico das curvas carga versus deflexão das 12 tíbias do subgrupo experimental (GE1T).

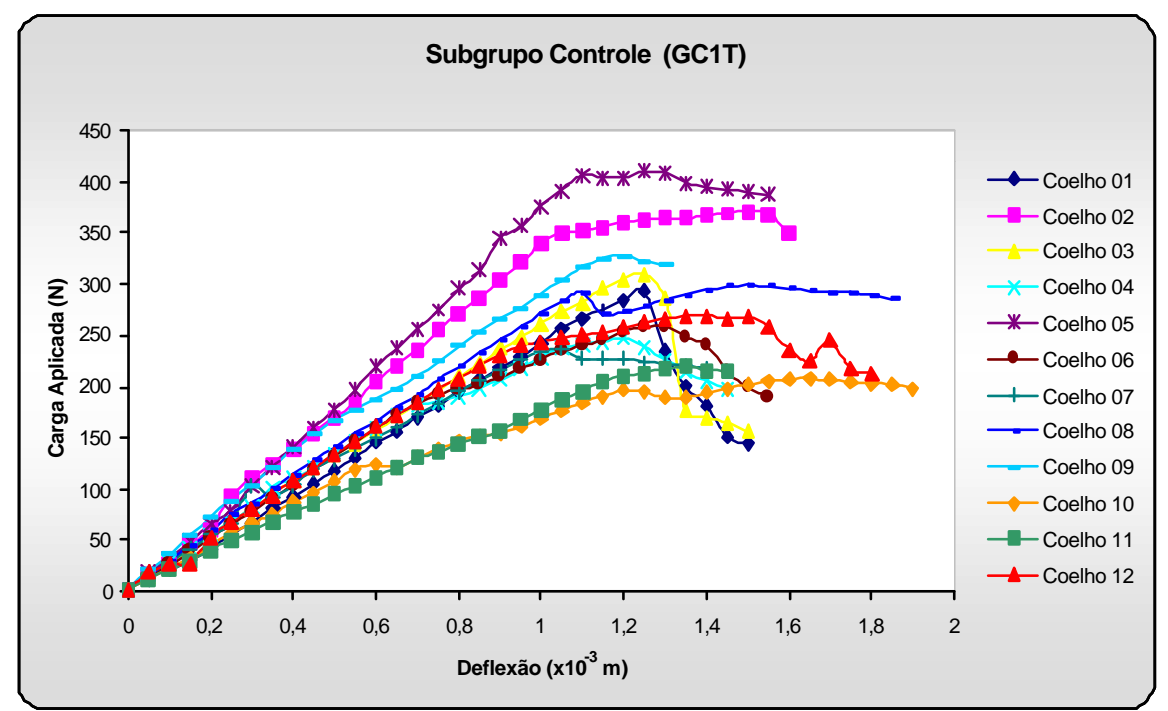

FIGURA 16 - Gráfico das curvas carga versus deflexão das 12 tíbias do subgrupo controle (GC1T). 


\subsubsection{1 - Deflexão no Limite de Proporcionalidade}

O valor médio da deflexão no limite de proporcionalidade para as tíbias do subgrupo experimental (GE1T) foi de $(1,15 \pm 0,20) \mathrm{mm}$ e o valor médio para as tíbias do subgrupo controle (GC1T) foi de $(1,15 \pm 0,31) \mathrm{mm}$. A figura 17 apresenta os gráficos comparativos das duas deflexões médias dos dois subgrupos. $\mathrm{Na}$ análise estatística dos subgrupos foi verificado que não houve diferença significativa entre si $(p=0,96)$.

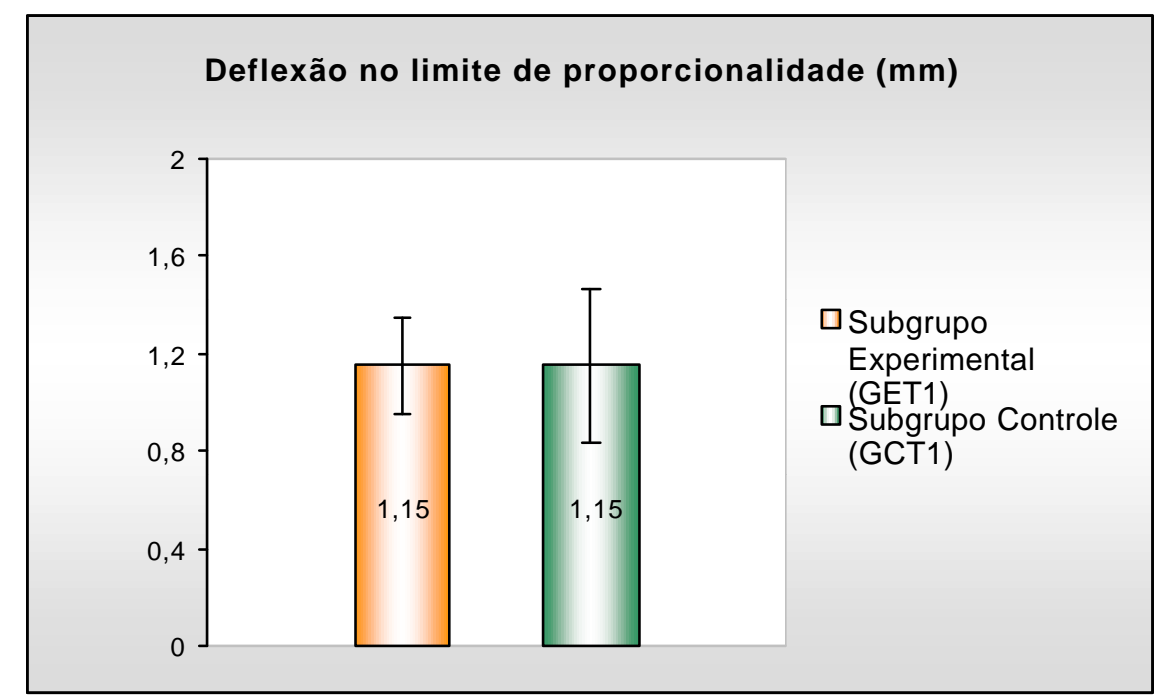

FIGURA 17 - Valores médios das deflexões no limite de proporcionalidade das tíbias dos subgrupos experimental (GE1T) e controle (GC1T). 


\subsubsection{2- Carga no Limite de Proporcionalidade}

O valor médio da carga aplicada no limite de proporcionalidade para as tíbias do subgrupo experimental (GE1T) foi de $(278,9 \pm 59,6) \mathrm{N}$ e de $(269,0 \pm 68,7) \mathrm{N}$ para as tíbias do subgrupo controle (GC1T). A figura 18 apresenta os valores médios da carga aplicada no limite de proporcionalidade para os dois subgrupos. Quando comparado os dois subgrupos não foi verificado diferença estatística significativa entre eles $(p=0,71)$.

\section{Carga no limite de proporcionalidade (N)}

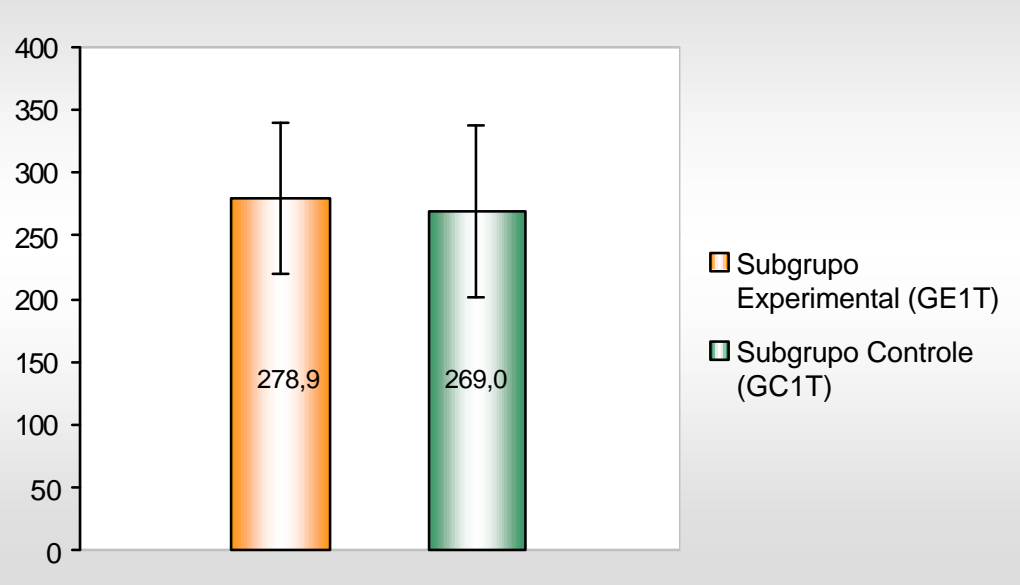

FIGURA 18 - Valores médios das cargas aplicadas no limite de proporcionalidade das tíbias dos subgrupos experimental (GE1T) e controle (GC1T). 


\subsubsection{3 - Rigidez}

O valor médio da rigidez das tíbias do subgrupo experimental (GE1T) foi de $(243,25 \pm 42,28) \times 10^{3} \mathrm{~N} / \mathrm{m}$ e para as tíbias do subgrupo controle (GC1T), o valor médio da rigidez foi de $(251,25 \pm 57,31) \times 10^{3} \mathrm{~N} / \mathrm{m}$. A figura 19 apresenta os valores médios na forma de gráfico. $\mathrm{Na}$ comparação entre os dois subgrupos não foi observada diferença estatística significativa entre si $(p=0,71)$.

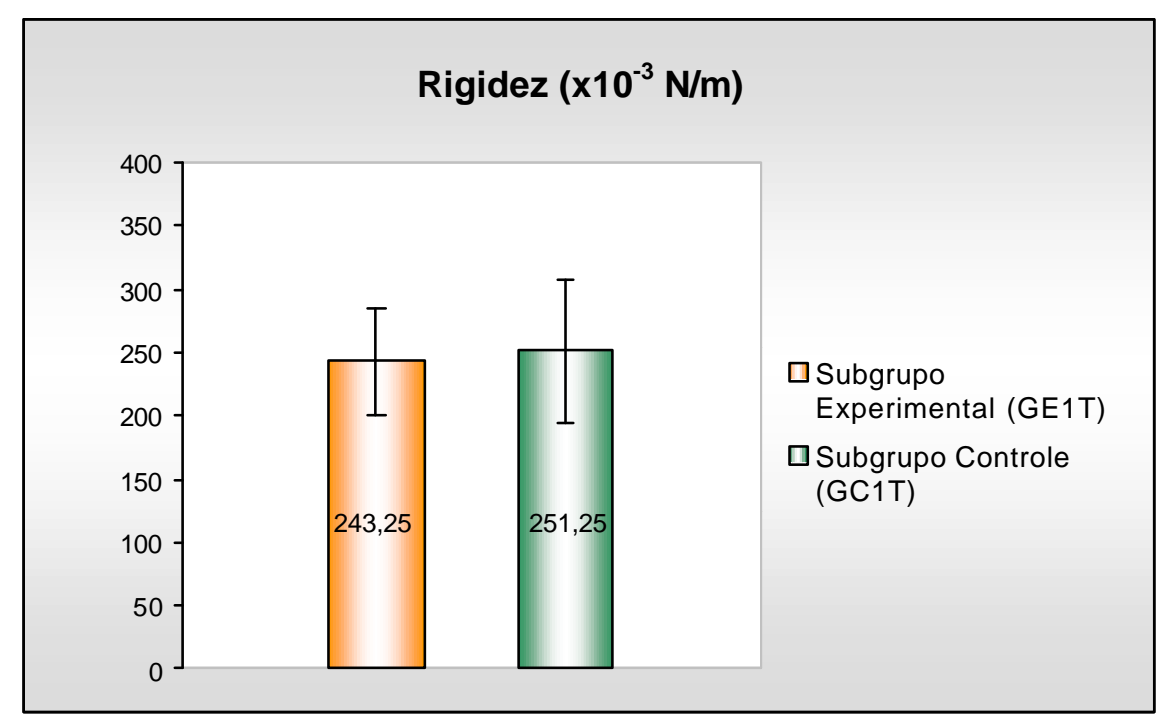

FIGURA 19 - Valores médios da rigidez das tíbias dos subgrupos experimental (GE1T) e controle (GC1T). 


\subsubsection{4 - Carga Máxima}

A carga aplicada máxima média das tíbias dos animais do subgrupo experimental (GE1T) foi de $(303,05 \pm 55,31) \mathrm{N}$, e para as tíbias do subgrupo controle $(\mathrm{GC} 1 \mathrm{~T})$ foi de $(285,75 \pm 58,47) \mathrm{N}$. A figura 20 apresenta estes valores na forma de gráfico. Quando comparado os dois subgrupos não foi verificado diferença estatística significativa entre eles $(p=0,46)$.

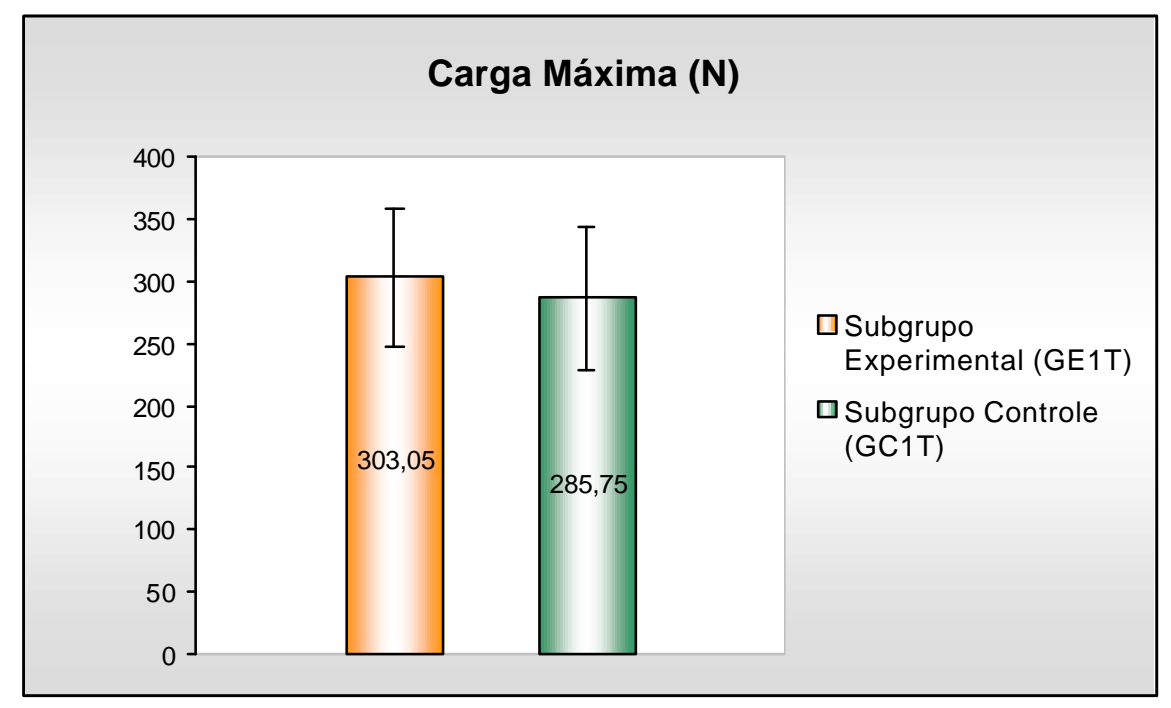

FIGURA 20 - Valores médios das cargas máximas nas tíbias do subgrupo experimental (GE1T) e controle (GC1T). 


\subsubsection{5 - Resiliência}

A resiliência média das tíbias do subgrupo experimental (GE1T) foi de $(139,75 \pm 28,88) \times 10^{-3} \mathrm{~J}$ e das tíbias do subgrupo controle (GC1T) foi de $(145,33 \pm 44,40) \times 10^{-3} \mathrm{~J}$. Estes valores médios também estão apresentados na figura 21. Quando realizado a comparação entre os subgrupos não foi observado diferença estatística significativa $(p=0,71)$.

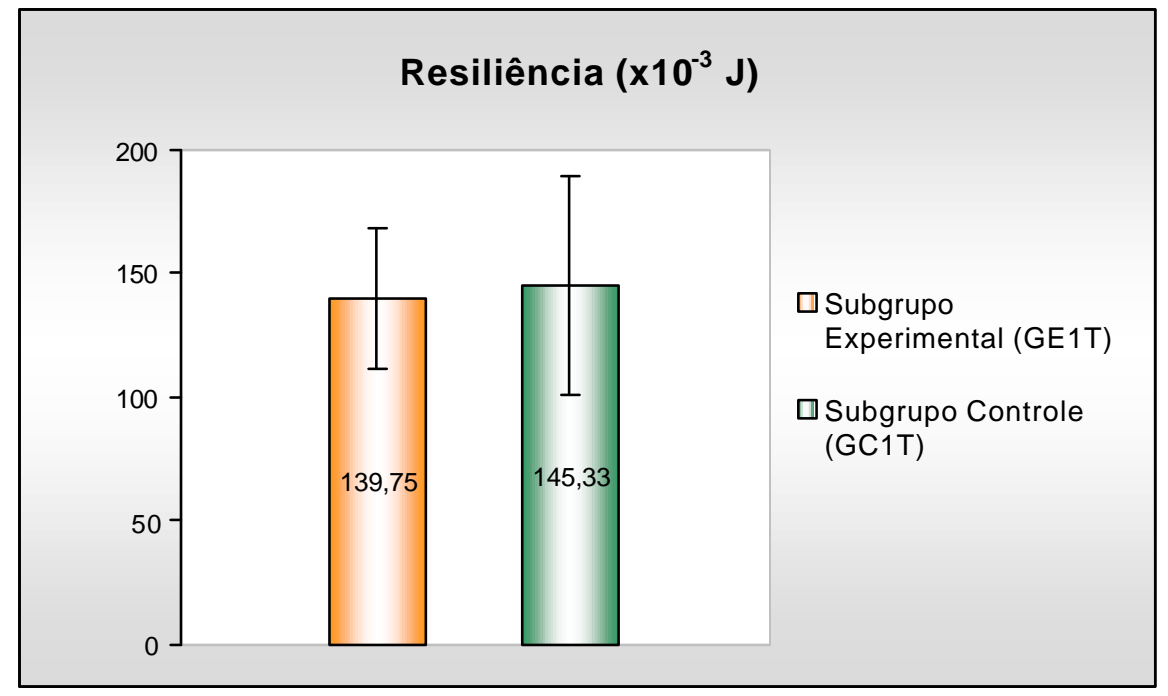

FIGURA 21 - Valores médios da resiliência das tíbias do subgrupo experimental (GE1T) e controle (GC1T). 


\section{4 - Medidas Antropométricas e Propriedades Mecânicas dos Fêmures como Estrutura}

As mesmas medidas e propriedades determinadas e analisadas para as tíbias, também foram realizadas e obtidas para os fêmures.

\subsubsection{Peso femural}

Os pesos médios dos fêmures do subgrupo experimental (GE1F) e do subgrupo controle (GC1F) foram de $(13,05 \pm 1,80) \mathrm{g}$ e $(13,15 \pm 2,30) \mathrm{g}$ respectivamente. A figura 22 apresenta estes valores representados graficamente. Comparando-se os pesos dos dois subgrupos, não foi observada diferença estatística significativa entre eles $(p=0,99)$.

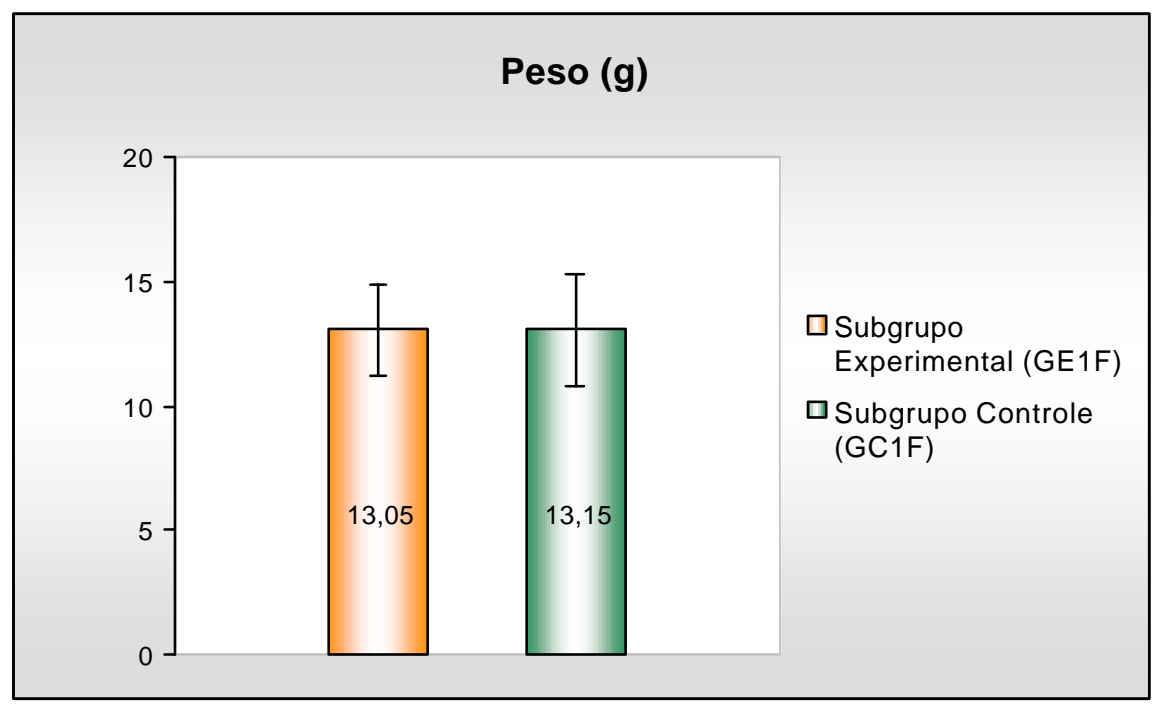

FIGURA 22 - Valores médios dos pesos dos fêmures do subgrupo experimental (GE1F) e controle (GC1F). 


\subsubsection{Comprimento Longitudinal}

O valor médio do comprimento dos fêmures do subgrupo experimental (GE1F) foi de $(95,3 \pm 2,9) \mathrm{mm}$ e o valor médio das fêmures do subgrupo controle $(G C 1 F)$ foi de $(95,6 \pm 2,2) \mathrm{mm}$. A figura 23 apresenta estes valores graficamente. $\mathrm{Na}$ comparação realizada entre os comprimentos dos fêmures dos dois subgrupos, não foi observada diferença estatisticamente significante $(p=0,75)$.

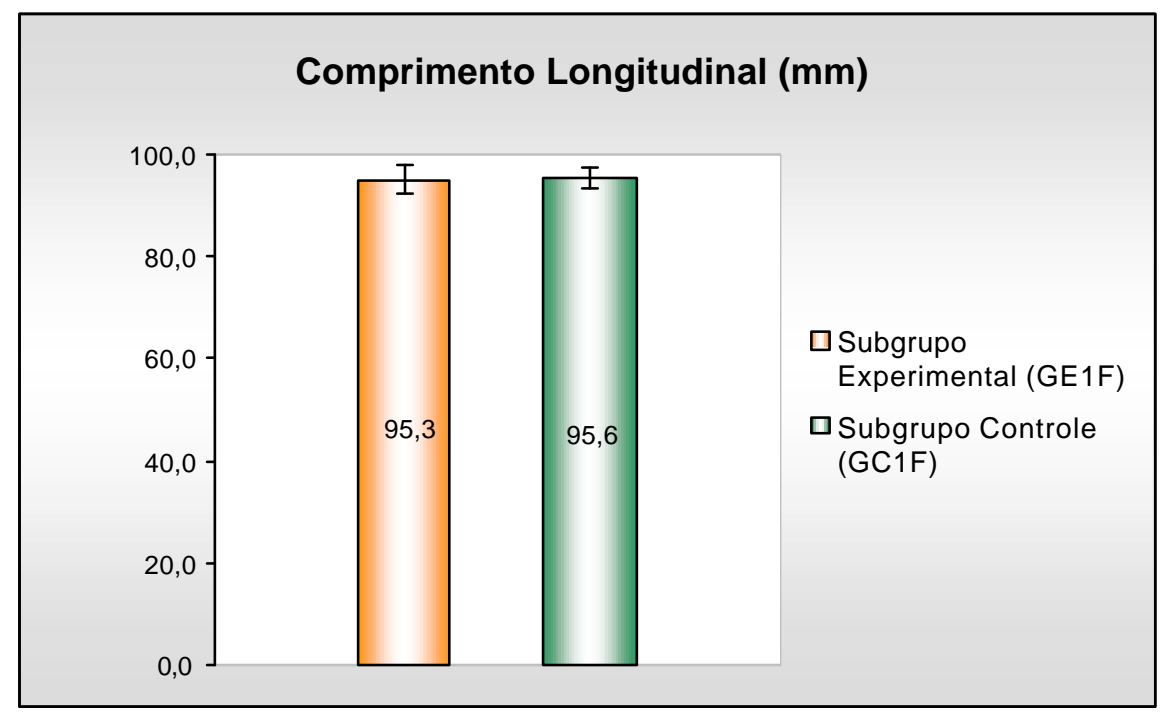

FIGURA 23 - Valores médios do comprimento dos fêmures do subgrupo experimental (GE1F) e controle (GC1F). 


\subsubsection{Comprimento Circunferencial}

O valor médio do comprimento circunferencial obtido da região central da diáfise dos fêmures do subgrupo experimental (GE1F) foi de $(29,3$ $\pm 2,8) \mathrm{mm}$ e dos fêmures do subgrupo controle $(\mathrm{GC1F})$ foi de $(30,8 \pm 2,4)$ $\mathrm{mm}$. A figura 24 apresenta estes valores graficamente. Quando comparados entre si, não foi observada diferença estatística significativa entre os subgrupos experimental e controle $(p=0,18)$.

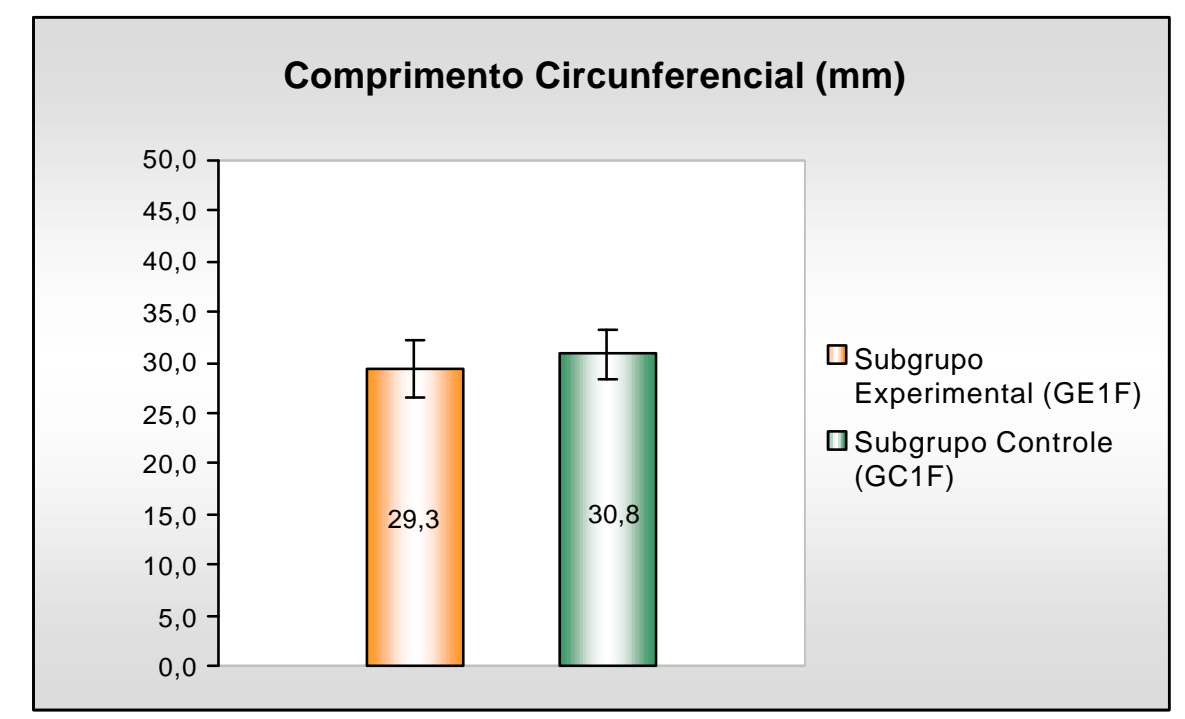

FIGURA 24 - Valores médios do comprimento dos fêmures do subgrupo experimental (GE1F) e controle (GC1F). 


\subsection{4 - Gráficos Carga versus Deflexão}

A figura 25 apresenta os gráficos de carga aplicada em função da deflexão, obtidos dos ensaios mecânicos de flexão em três pontos de fêmures das 12 coelhas tratadas a base de corticóides (GE1F) e a figura 26 apresenta os gráficos de 12 fêmures das coelhas tratadas com solução salina (GC1F).

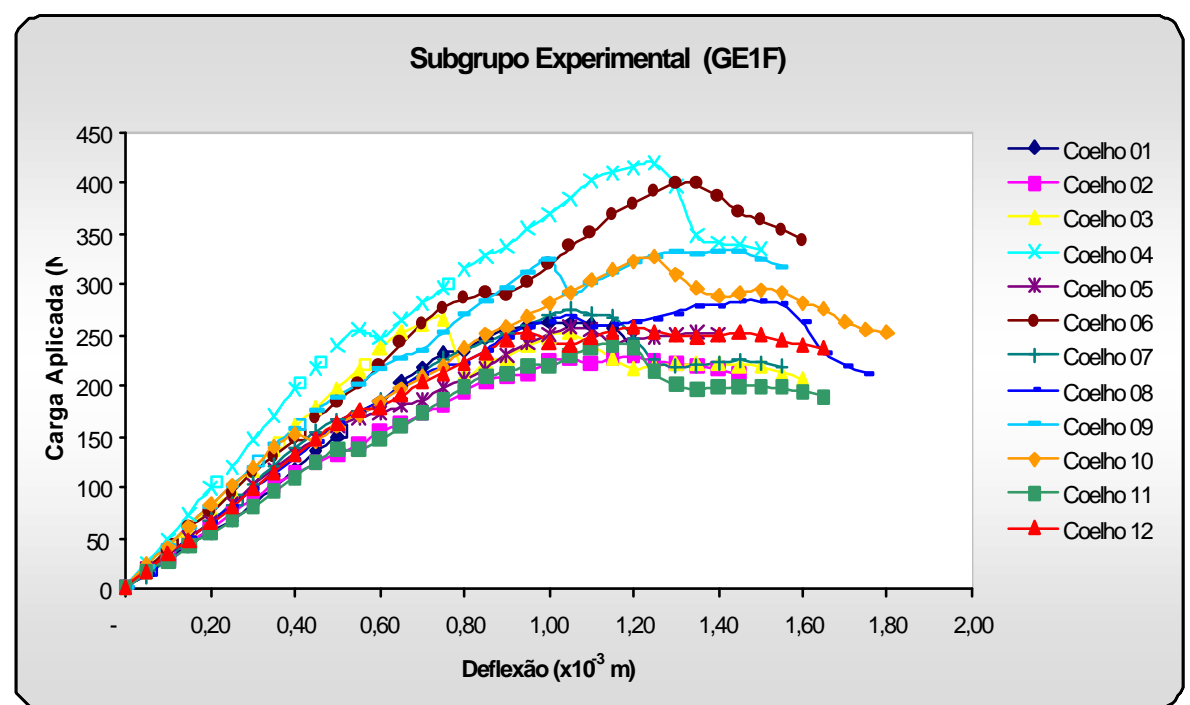

FIGURA 25 - Gráfico das curvas carga versus deflexão dos 12 fêmures do subgrupo experimental (GE1F).

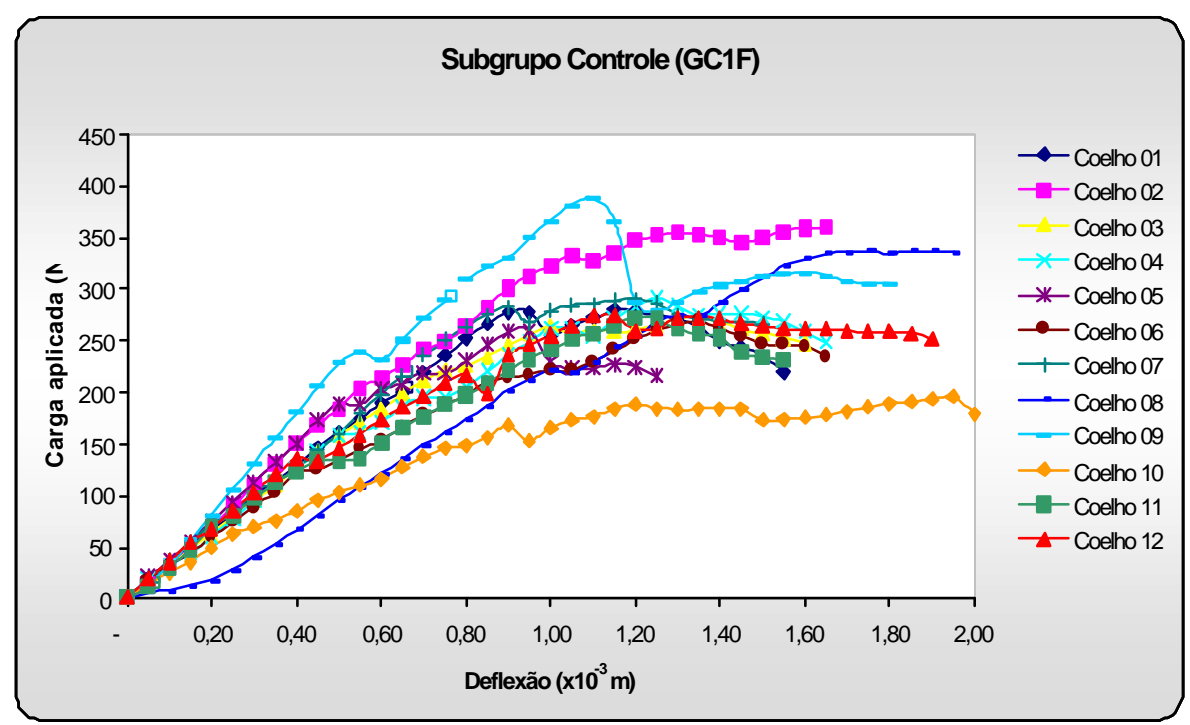

FIGURA 26 - Gráfico das curvas carga versus deflexão dos 12 fêmures do subgrupo controle (GC1F). 


\subsubsection{1 - Deflexão no Limite de Proporcionalidade}

O valor médio da deflexão no limite de proporcionalidade para os fêmures do subgrupo experimental (GE1F) foi de $(0,79 \pm 0,28) \mathrm{mm}$ e 0 valor médio para fêmures do subgrupo controle $(\mathrm{GC1F})$ foi de $(0,83 \pm$ $0,27) \mathrm{mm}$. A figura 27 apresenta os gráficos comparativos das deflexões médias dos dois subgrupos. Quando comparados os valores dos subgrupos, foi verificado que não houve diferença estatística significativa entre eles $(p=0,77)$.

Deflexão no limite de proporcionalidade dos fêmures $(\mathrm{mm})$

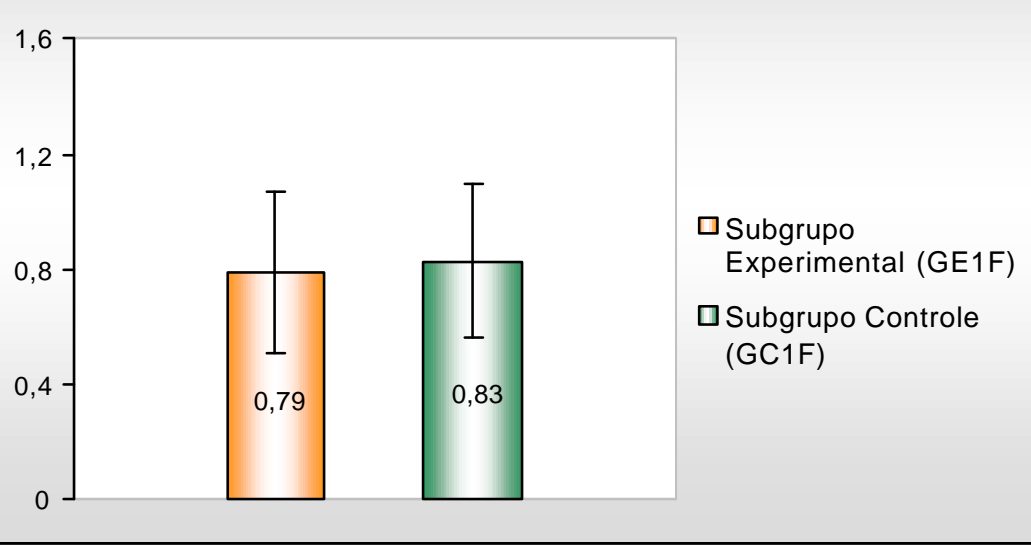

FIGURA 27 - Valores médios das deflexões no limite de proporcionalidade dos fêmures do subgrupo experimental (GE1F) e controle (GC1F). 


\subsubsection{2 - Carga no Limite de Proporcionalidade}

O valor médio da carga aplicada no limite de proporcionalidade para os fêmures do subgrupo experimental (GE1F) foi de $(230,1 \pm 67,5) \mathrm{N} \mathrm{e}$ de $(219,9 \pm 70,2) \mathrm{N}$ para os fêmures do subgrupo controle (GC1F). A figura 28 apresenta os valores médios da carga no limite de proporcionalidade para os dois subgrupos. Quando realizada a comparação entre os subgrupos não foi verificada diferença estatística significativa entre eles $(p=0,72)$.

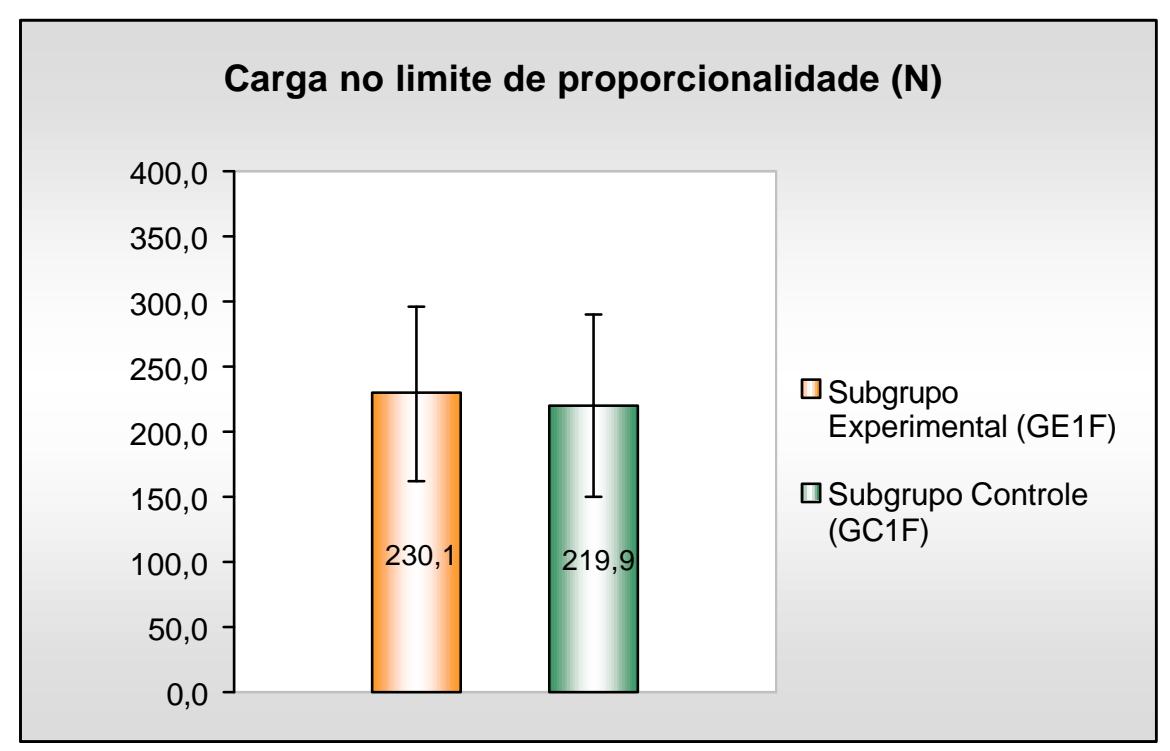

FIGURA 28 - Valores médios das cargas no limite de proporcionalidade dos fêmures do subgrupo experimental (GE1F) e controle (GC1F). 


\subsubsection{3 - Rigidez}

O valor médio da rigidez dos fêmures do subgrupo experimental (GE1F) foi de $(318,42 \pm 64,96) \times 10^{3} \mathrm{~N} / \mathrm{m}$ e para os fêmures do subgrupo controle (GC1F), o valor médio da rigidez foi de $(273,92 \pm 58,08) \times 10^{3} \mathrm{~N} / \mathrm{m}$. A figura 29 apresenta os valores médios na forma de gráfico. $\mathrm{Na}$ comparação entre os dois subgrupos não foi observada diferença estatística significativa $(p=0,71)$.

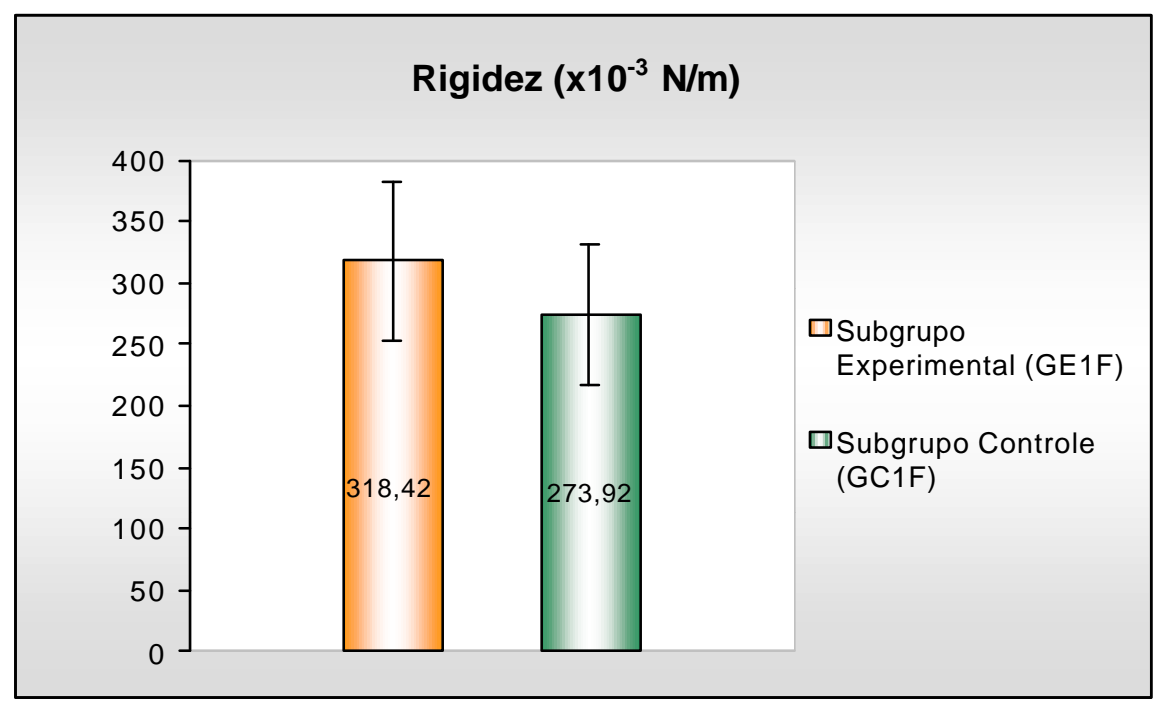

FIGURA 29 - Valores médios da rigidez dos fêmures do subgrupo experimental (GE1F) e controle (GC1F). 


\subsubsection{4 - Carga Máxima}

A carga aplicada máxima média dos fêmures dos animais do subgrupo experimental (GE1F) foi de $(296,65 \pm 58,19) \mathrm{N}$, e para os fêmures do subgrupo controle $(\mathrm{GC1F})$ foi de $(288,07 \pm 47,28) \mathrm{N}$. A figura 30 representa graficamente estes valores. Na realização da comparação entre os subgrupos não foi verificada diferença estatística significativa entre eles $(p=0,58)$.

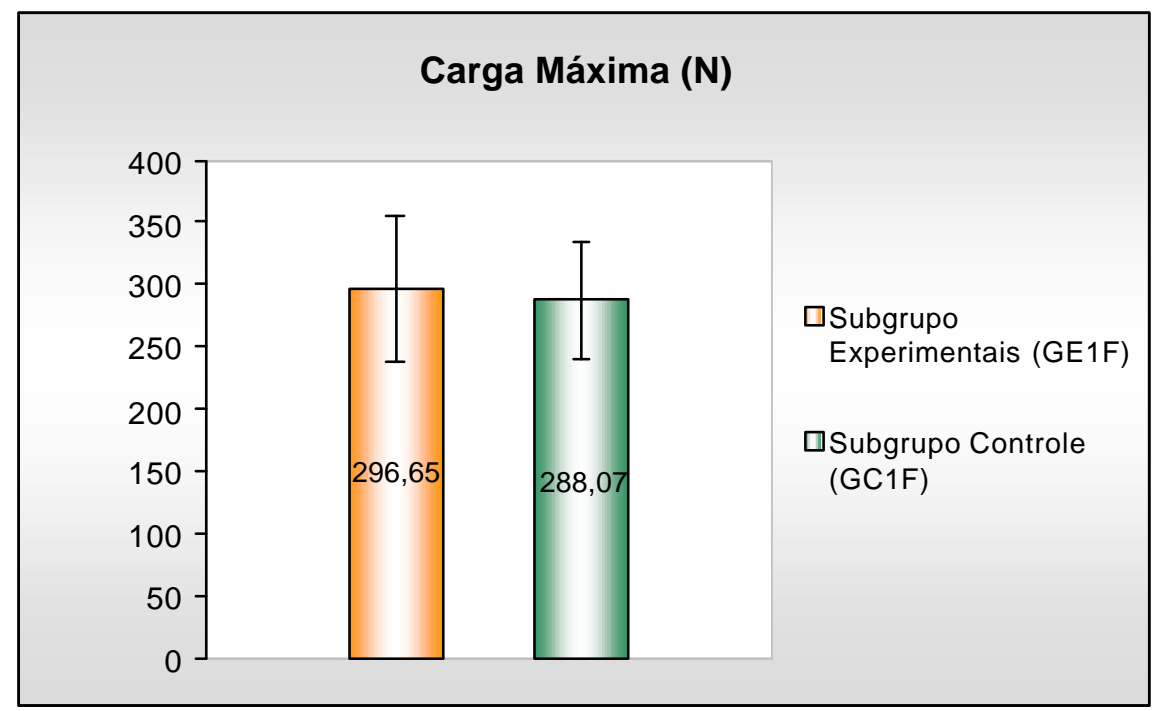

FIGURA 30 - Valores médios das cargas máximas dos fêmures no subgrupo experimental (GE1F) e controle (GC1F). 


\subsubsection{5 - Resiliência}

A resiliência média dos fêmures do subgrupo experimental (GE1F) foi de $(91,50 \pm 55,98) \times 10^{-3} \mathrm{~J}$ e dos fêmures do subgrupo controle (GC1F) foi de $(83,08 \pm 43,79) \times 10^{-3} \mathrm{~J}$. Estes valores médios também estão apresentados graficamente na figura 31. Quando realizado a comparação entre os subgrupos não foi observado diferença estatística significativa $(p=0,68)$.

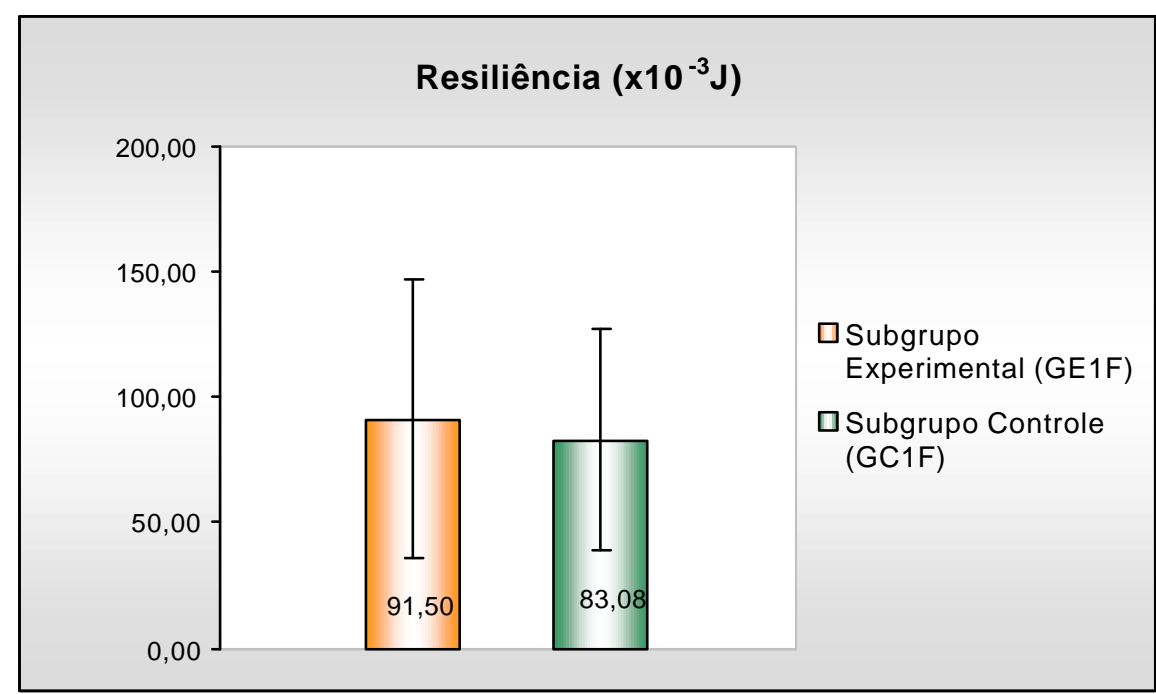

FIGURA 31 - Valores médios de resiliência dos fêmures no subgrupo experimental (GE1F) e controle (GC1F). 


\section{5 - Avaliação dos Ossos como Material}

Nesta avaliação foram realizadas: uma análise qualitativa da arquitetura trabecular e somente a propriedade mecânica da tensão máxima foi realizada obtida de cada CDP, através de ensaios de flexão em três pontos para os CDPs obtidos dos fêmures representados pelos subgrupos GC2F e GE2F, e ensaios de compressão nos CDPs obtidos das vértebras representados pelos subgrupos GC2V e GE2V.

\subsection{1 - Análise Qualitativa da Arquitetura Trabecular}

Para o método de análise qualitativa dos CDPs das vértebras ensaiadas foi realizado comparaçôes entre os subgrupos (GE2V e GC2V), onde foi possível evidenciar alterações significativas na estrutura macroscópica de alguns o ossos trabeculares de coelhas que foram submetidas a administração de corticosteróides.

As figuras 32 e 33 ilustram alterações macroscópicas observadas nas comparações dos CDPs de vértebras dos subgrupo controle (GC2V) e subgrupo experimental (GE2V) antes e após a realização dos ensaios mecânicos de compressão, respectivamente.

$\mathrm{Na}$ figura 32B pode ser observado um espaçamento entre as trabéculas ósseas quando comparada ao CDPs do subgrupo controle (GC2V) antes da realização do ensaio mecânico de compressão. A figura 33 $B$ indica um esmagamento trabecular observado em alguns CDPs do subgrupo GE2V após a realização dos ensaios. 


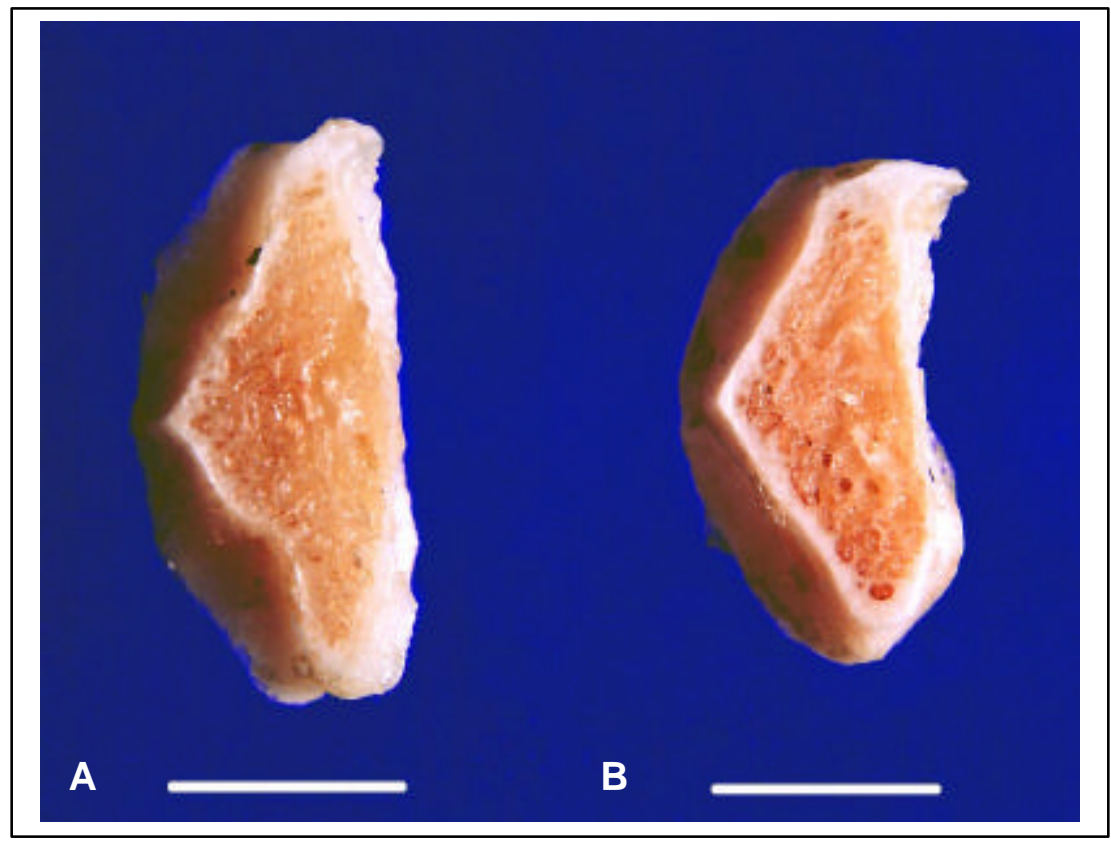

FIGURA 32 - (A) CDP da vértebra do subgrupo GC2V antes da realização do ensaio mecânico. A barra de medida representada na figura indica a dimensão de comprimento de $7 \mathrm{~mm}$ (B) CDP da vértebra do subgrupo GE2V antes da realização do ensaio mecânico. $A$ barra de medida representada na figura indica a dimensão de comprimento de $6 \mathrm{~mm}$.

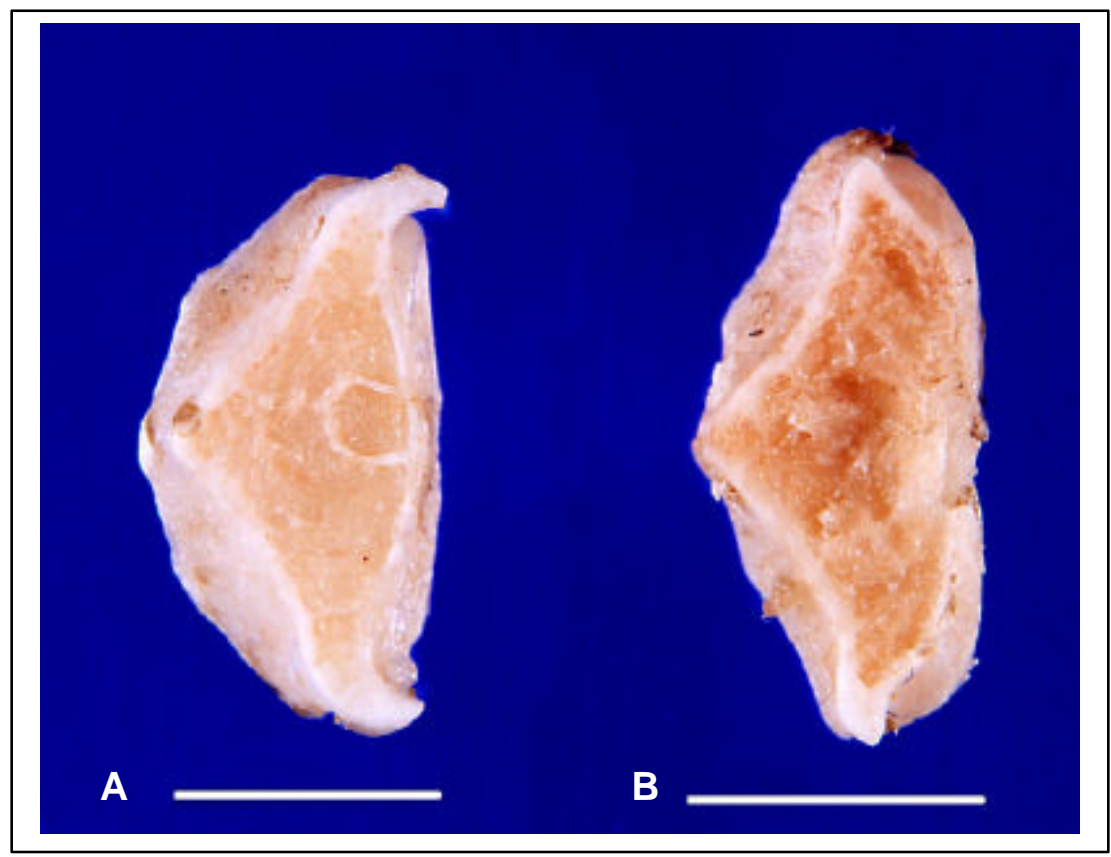

FIGURA 33 - (A) CDP da vértebra do subgrupo GC2V após a realização do ensaio mecânico. $A$ barra de medida representada na figura indica a dimensão de comprimento de $6 \mathrm{~mm}$ (B) CDP da vértebra do subgrupo GE2V após a realização do ensaio mecânico. A barra de medida representada na figura indica a dimensão de comprimento de $7 \mathrm{~mm}$. 


\subsubsection{Tensão Máxima dos CDPs de fêmures}

O valor médio da tensão máxima dos CDPs obtidos de fêmures no subgrupo experimental (GE2F) foi de $(218 \pm 16) \mathrm{MPa}$ e no subgrupo controle (GC2F) foi de $(224 \pm 65) \mathrm{MPa}$. A figura 34 apresenta os gráficos comparativos das tensões médias dos dois subgrupos. Quando realizada a comparação entre os seus valores encontrados não foi verificada diferença estatística significativa entre eles $(p=0,1104)$.

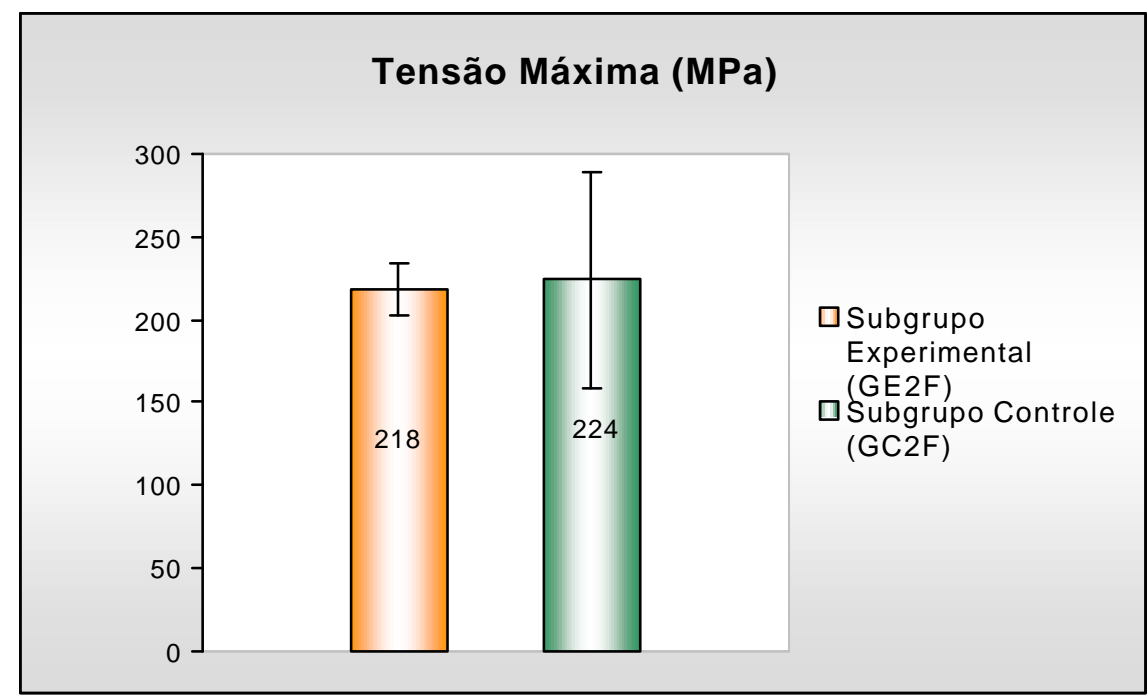

FIGURA 34 - Valores médios das tensões máximas dos fêmures do subgrupo experimental (GE2F) e controle (GC2F). 


\subsubsection{Tensão Máxima dos CDPS das Vértebras}

O valor médio da tensão máxima dos CDPs obtidos das vértebras no subgrupo experimental (GE2V) foi de $(14,28 \pm 9,60) \mathrm{MPa}$ e para subgrupo controle (GC2V) foi de $(21,66 \pm 5,30) \mathrm{MPa}$. A figura 35 apresenta os gráficos comparativos das tensões médias dos dois subgrupos. $\mathrm{Na}$ comparação entre os dois subgrupos não foi verificada diferença estatística significativa entre eles $(p=0,1751)$.

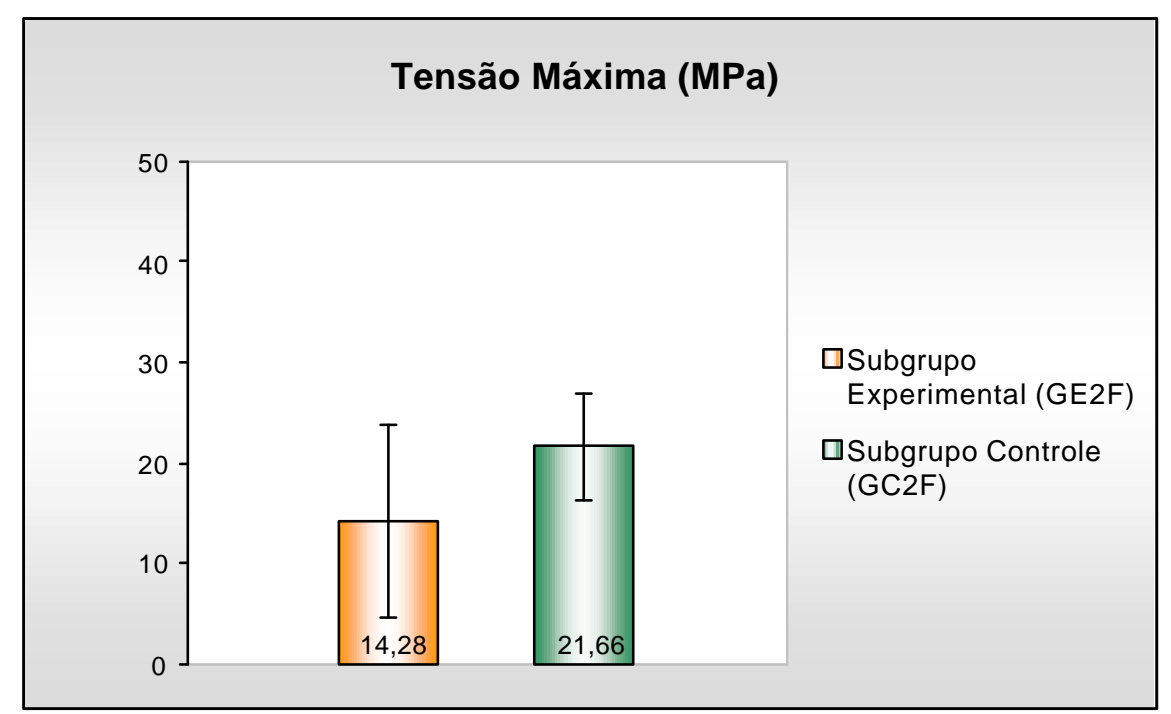

FIGURA 35 - Valores médios das tensões máximas das vértebras do subgrupo experimental (GE2V) e controle (GC2V). 


\section{0 - DISCUSSÃO}

O organismo humano produz o cortisol, um tipo de corticóide que regula as inúmeras atividades metabólicas, que ocorrem praticamente em todo o sistema exercendo uma ação anti-inflamatória e imunossupressora reconhecida. Em função do conhecimento destas importantes propriedades, foram pesquisados e desenvolvidos corticóides mais potentes e com ação mais prolongada para serem utilizados no tratamento das diversas patologias inflamatórias crônicas e também para servir como agente imunossupressor para os casos de transplante de órgãos.

Existem na literatura muitos trabalhos de pesquisa experimental em animais com o objetivo de se observar as alterações morfológicas e funcionais, em vários tipos de tecidos, induzidos pelo uso de corticosteróides sistêmicos, principalmente sobre os ossos da coluna vertebral e colo do fêmur. A corticoterapia induz a alterações da densidade óssea mineral de ossos esponjosos, como o da coluna lombar (BHATTOA, 2002; STAFFORD et al., 2000; NEGRl et al., 1999; SELBY et al., 2000; $A D A C H I, 2001$. Porém, não foi encontrado na literatura nenhum estudo que investigasse as possíveis alterações das propriedades mecânicas em ossos longos de coelhas submetidas a ação da corticoterapia através de ensaio de flexão em três pontos. Sendo assim, nossa proposta foi de investigar as possíveis alterações nas propriedades mecânicas do osso cortical e trabecular quando submetido a corticoterapia com altas doses, 
pois segundo Gilman (1996), o osso cortical também pode desenvolver osteoporose e sofrer fraturas a mínimos traumas em decorrência de tratamento com corticosteróides.

Um estudo neste sentido é de grande importância pois, segundo Huang \& Zheng (1999), o equilíbrio do hormônio esteróide no sangue, mantém um balanço adequado entre a produção e reabsorção óssea pelos osteoblastos e osteoclastos respectivamente. Sendo assim, quando um paciente está sob tratamento com corticóides em altas doses e/ou por tempo prolongado ou quando este equilíbrio hormonal fica comprometido por motivos endógenos ou exógenos, haverá um desequilíbrio entre a produção e reabsorção óssea.

Alguns estudos em humanos e em animais relatam que o uso de corticóides por via oral ou parenteral em altas doses e por períodos prolongados levam a uma diminuição da massa óssea e a miopatias do músculo estriado pelo aumento do catabolismo celular. (COMMES, 1965; D'AGOSTINO \& CHIGA 1966; AFIFI \& BERGMAN, 1969).

Lloyd et al., (2000) avaliando a densidade óssea de uma mulher de 52 anos, que utilizou corticoterapia por tempo prolongado e com baixas doses, não encontraram alteração da densidade óssea das tíbias e fíbulas. No entanto, Bhattoa (2002) observou a diminuição da densidade óssea mineral da coluna lombar de mulheres que utilizam doses altas de corticosteróides por longo tempo. Sendo assim, neste trabalho, utilizamos a corticoterapia não só por tempo prolongado, como também em altas doses.

Os animais utilizados nesta pesquisa foram coelhas da raça Nova Zelândia, pois segundo Yamamoto et al. (1997) as alterações provocadas pela metilprednisolona nestes animais são semelhantes àquelas que ocorrem em humanos.

A dose diária de corticóides aqui utilizada foi determinada buscando-se um equilíbrio entre uma quantidade de droga capaz de induzir alterações anti-inflamatórias acentuadas e efeitos colaterais que não impedissem a sobrevida prolongada dos animais. Em estudos pilotos 
realizado com os animais, doses maiores que $2 \mathrm{mg} / \mathrm{Kg} / \mathrm{dia}$ ou administração de medicamento realizados por mais de 3 semanas, não foram bem tolerados pelos animais, que em sua maioria morreram. Em humanos é sabido que a corticoterapia em dose elevada, pode levar ao bloqueio da resposta inflamatória e também pode suprimir o sistema imunológico. Sendo assim, sugerimos que as doses utilizadas nesta pesquisa podem ser consideradas altas e o tempo de administração do medicamento pode ser considerado longo para as coelhas, pois segundo Yasuda et al., (2003) doses de prednisolona de $7,5 \mathrm{mg} / \mathrm{dia}$ ou mais leva a uma diminuição de massa óssea, aumentando o risco de fraturas.

Embora todos os glicocorticóides apresentem no geral um perfil de efeitos colaterais semelhantes, existem diferenças sutis, bem conhecidas e clinicamente importantes, entre os diferentes tipos de fármacos (Silva, 2003). A metilprednisolona quando administrada de forma sistêmica apresenta uma meia vida biológica de 12 a 36 horas, enquanto o cortisol, apresenta meia vida biológica de 8 a 12 horas. Sendo assim, nesta pesquisa, fez-se a opção de utilizar a metilprednisolona, pois a mesma proporciona a facilitação de apenas uma administração diária. O período do dia escolhido para a administração foi o matutino, pois segundo Rang et al., (2001) a concentração de corticóides endógenos no sangue apresenta-se elevada na manhã e reduzida a noite. 
As tíbias e fêmures dos grupos GC1 e GE1 foram mantidos congelados no freezer até a realização dos ensaios mecânicos. Este procedimento proporcionou ganho de tempo e rendimento, pois, possibilitou juntar uma maior quantidade de ossos para os dias de realização dos ensaios. Havia ainda a dependência dos experimentos das outras duas dissertações, onde foram utilizados o diafragma, músculo gastrocnêmio e traquéia, no qual deveriam ser ensaiadas ainda a fresco. $O$ congelamento provavelmente, não influenciou nos resultados finais, pois segundo Sedlin \& Hirsch (1966), o congelamento e o subseqüente aquecimento do osso, não provoca diferença significativa em suas propriedades mecânicas.

Lee \& Pelker (1985), realizaram ensaios mecânicos de cisalhamento na cartilagem de crescimento proximal das tíbias de coelhos a fresco e após congelamento. Estes autores não verificaram diferenças significativas nas propriedades mecânicas entre os dois grupos. $O$ aproveitamento de parte dos mesmos animais que foram utilizadas também em outras duas dissertações, houve uma importante otimização do tempo de experimento, dos recursos necessários e disponibilidade de uso nos laboratórios onde foram realizados os experimentos, havendo também minimização dos custos com animais e dos medicamentos utilizados.

O osso é um material biológico e por isto deve existir uma relação entre os processos físicos e biológicos. Portanto, o conhecimento da complexidade de sua estrutura, e das suas propriedades mecânicas é importante e necessário. Para isto, este trabalho propôs a estudar os ossos longos (tíbias e fêmures) de coelhas submetidas a administração a base de corticóide. Esta análise é importante, pois podemos verificar as influências geométricas e mecânicas considerando cada osso como uma estrutura, analisando como um todo. 
Uma outra análise importante realizada foi a avaliação do osso como material, ou seja, analisar as propriedades mecânicas dos tecidos ósseos cortical e trabecular, através de CDPs dos ossos correspondentes.

Os ensaios mecânicos de flexão em três pontos das tíbias e fêmures foram realizados posicionando-se os ossos de maneira que a aplicação da carga na região central da diáfise óssea fosse sempre aplicada no sentido ântero-posterior. Esta padronização foi escolhida somente pela facilidade de se posicionar os ossos neste sentido sobre o acessório para realização dos ensaios, pois segundo os achados de Pessan (1996), não existem diferenças estatísticas significantes quando são realizados ensaios de flexão em três pontos na face côncava ou convexa do fêmur.

A realização dos ensaios mecânicos de flexão em três pontos deste trabalho não apresentou qualquer problema de ordem técnica, pois este tipo de ensaio já foi e é utilizado com freqüência para determinar as propriedades mecânicas do osso como uma estrutura. A equipe do Laboratório de Bioengenharia da FMRP - USP já têm experiência neste tipo de ensaio, por isso, aproveitou-se os acessórios existentes para a realização do ensaio de flexão em três pontos proposto nesta pesquisa. Um vão livre de $60 \mathrm{~mm}$ foi utilizado, pois assim o osso ficaria apoiado na suas extremidades e a carga foi aplicada na região central da diáfise, permitindo a aplicação da carga na região cortical dos ossos ensaiados, para que se pudesse avaliar as possíveis alterações nas propriedades mecânicas do osso cortical submetido a corticoterapia como proposto nesta pesquisa.

Com relação à técnica de ensaios de compressão utilizada neste trabalho, baseada no trabalho realizado pelos autores Hogan et al., 2000, apresentamos mais uma metodologia de ensaio de materiais interessante e importante, principalmente para se determinar as propriedades mecânicas de ossos trabeculares, que geralmente tem maior resistência os esforços de compressão do que de tração.

Comparando-se os pesos iniciais com os pesos finais dos animais tratados com corticosteróide, observamos uma perda de peso para 
no grupo experimental. Esta mesma comparação e discussão foram apresentadas também por Silva (2002) e por Silva (2003). Esta perda de peso provavelmente está relacionada com o aumento do catabolismo celular e conseqüentemente resultando na diminuição da massa muscular e atrofia dos tecidos linfóides, como verificados por Gilman, (1996).

Segundo os pesquisadores Capaccio et al., (1985) e Nava et al., (1996), uma administração de altas doses de corticosteróide pode provocar vários efeitos deletérios no organismo pela ação catabólica desta droga agindo particularmente, no primeiro período de tratamento, nos grupos musculares. Provavelmente, essa é uma das explicações do motivo pelo qual não foram encontradas alterações significativas nas propriedades ósseas investigadas neste trabalho, pois como o osso é um tecido mais rígido, antes de sofrer qualquer alteração estrutural, haveria primeiro um efeito da droga sobre os tecidos moles, tais como músculos e cartilagens.

Porém, nos trabalhos de Silva (2002) e Silva (2003) realizados em outros tipos de tecidos (músculo gastrocnêmio, diafragma e traquéia) submetidos a ensaios mecânicos também não foram encontradas diferenças significativas nas propriedades mecânicas investigadas dos tecidos dos animais tratados a base de corticóide comparados com os tratados com solução salina, lembrando que os tratamentos realizados nos animais foram iguais para os três trabalhos.

A não observância de alterações significativas nas propriedades mecânicas estruturais dos ossos longos de coelhas quando submetidas ao tratamento a base de corticóde, provavelmente poderia resultar do período, da quantidade ou do tipo de corticosteróides administrado, bem como da idade do animal utilizado. No entanto, na análise do osso como material, verificamos macroscopicamente que nos CDPs obtidos das vértebras dos animais submetidos ao tratamento a base de corticóde, havia uma maior desorganização da arquitetura óssea trabecular que nos CDPs das vértebras dos animais que não foram submetidos ao mesmo tratamento. 
Quando comparamos os resultados das propriedades mecânicas estruturais, como a carga no limite de proporcionalidade e a rigidez, encontradas neste trabalho verificamos que parece haver uma tendência (em valor absoluto) para que os valores médios do grupo controle sejam maiores que os do grupo experimental. Porém, estatisticamente, não foram verificadas diferenças significativas em todas as comparações realizadas das propriedades mecânicas analisadas, para a tíbia e fêmur. $\mathrm{E}$ quando observamos os valores das tensões máximas também verificamos que os maiores valores sempre foram os dos CDPs controles. Mas, mesmo com esta ocorrência não foi observada diferença significativa da propriedade mecânica analisada nestes subgrupos.

Segundo os autores Eberhardt et al., em 2001, altas concentrações de glicorticóides podem causar danos ósseos por mecanismo que inclui os osteócitos e a morte de osteoclastos. Estes autores observaram ainda que as alterações causadas pelos glicorticóides são particularmente maiores no tecido ósseo subarticular trabecular do fêmur do que no restante do mesmo. Estas observações foram realizadas no estudo das mudanças na atividade celular de fêmures de coelhos tratados com glicorticóides. Os coelhos foram tratados com injeções intramusculares de metilprednisolona com doses de 0,7 e 1,7 mg/Kg/dia. Estas doses foram ajustadas semanalmente de acordo com o peso dos animais. $O$ tratamento foi realizado por 28 dias. Após a eutanásia dos animais e retirados os fêmures, estes foram radiografados e realizados um estudo histológico dos mesmos. Estes autores não realizaram ensaios mecânicos nos ossos como realizamos neste trabalho. Outras duas diferenças básicas entre as duas metodologias foram com relação às doses aplicadas e o período de tratamento. A dose aplicada em nosso trabalho foi maior, mas com período de tratamento de uma semana a menos.

Apesar da administração de $2 \mathrm{mg} / \mathrm{Kg} /$ dia de metilprednisolona em coelhas adultas ao longo de 21 dias ter causado a diminuição do peso dos animais tratados quando comparado aos dos grupos controles e mesmo 
que macroscopicamente observamos alguma diferença na arquitetura do tecido ósseo trabecular de CDPs tratados e controle, este tratamento não levou as propriedades mecânicas a ter alterações estatisticamente significativas.

Em decorrência de não ter sido encontrada diferenças significativas nos resultados das propriedades mecânicas analisadas, entre os grupos experimentais investigados, sugerimos a continuidade desta linha de pesquisa variando, por exemplo, as doses aplicadas e o tempo de tratamento. 


\section{0 - CONCLUSÃo}

A administração de corticosteróides utilizada neste trabalho provocou uma diminuição dos pesos dos animais experimentais quando comparado aos dos grupos controles, porém não influenciou diretamente de modo significativo o comportamento das propriedades mecânicas analisadas nos ossos longos das coelhas, quando analisadas como estrutura.

Mesmo sendo observadas macroscopicamente algumas alterações na arquitetura do tecido ósseo trabecular de CDPs obtidos de coelhas induzida a corticoterapia quando comparadas ao controle, a administração do medicamento não interferiu na propriedade mecânica analisada, deste modo, não foi observado alterações estatisticamente significativas. 


\section{0 - ANEXOS}

I - Quadro 3: Peso de cada tíbia e fêmur das coelhas tratadas a base de corticóide (GE1T e GE1F) e solução salina (GC1T e GC1F)

II - Quadro 4: Comprimento longitudinal de cada tíbia e fêmur das coelhas tratadas a base de corticóide (GE1T e GE1F) e solução salina (GC1T e GC1F).

III - Quadro 5: Comprimento circunferencial de cada tíbia e fêmur das coelhas tratadas a base de corticóide (GE1T e GE1F) e solução salina (GC1T e GC1F).

IV - Quadro 6: Deflexão no limite de proporcionalidade de cada tíbia e fêmur das coelhas tratadas a base de corticóide (GE1T e GE1F) e solução salina (GC1T e GC1F).

N- Quadro 7: Carga no limite de proporcionalidade de cada tíbia e fêmur das coelhas tratadas a base de corticóide (GE1T e GE1F) e solução salina (GC1T e GC1F).

VI - Quadro 8: Rigidez de cada tíbia e fêmur das coelhas tratadas a base de corticóide (GE1T e GE1F) e solução salina (GC1T e GC1F).

VII - Quadro 9: Carga aplicada máxima de cada tíbia e fêmur das coelhas tratadas a base corticóide (GE1T e GE1F) e solução salina (GC1T e GC1F).

VIII - Quadro 10: Resiliência de cada tíbia e fêmur das coelhas tratadas a base de corticóide (GE1T e GE1F) e solução salina (GC1T e GC1F).

$I X$ - Ensaios de flexão em três pontos - CDP Fêmures Coelhas

$X$ - Ensaios de compressão - CDP de vértebras de coelhas 
I - QUADRO 3: Peso de cada tíbia e fêmur das coelhas tratadas a base de corticóide (GE1T e GE1F) e solução salina (GC1T e GC1F).

\begin{tabular}{|c|c|c|c|c|}
\hline \multicolumn{5}{|c|}{ PESO } \\
\hline \multirow[t]{2}{*}{ I } & \multicolumn{2}{|c|}{ TÍBIA } & \multicolumn{2}{|c|}{ FÊMUR } \\
\hline & CC (g) & SS (g) & $C C(g)$ & SS (g) \\
\hline C1 & 9,49 & 9,31 & 11,86 & 11,18 \\
\hline C2 & 10,97 & 13,26 & 12,34 & 14,89 \\
\hline C3 & 11,67 & 10,22 & 13,26 & 11,68 \\
\hline C4 & 11,97 & 11,97 & 14,35 & 13,29 \\
\hline C5 & 9,55 & 13,45 & 11,83 & 14,59 \\
\hline C6 & 10,67 & 9,70 & 11,97 & 11,29 \\
\hline $\mathrm{C7}$ & 10,39 & 9,56 & 12,29 & 12,58 \\
\hline C8 & 11,59 & 10,48 & 12,52 & 12,60 \\
\hline C9 & 11,48 & 15,14 & 18,14 & 18,85 \\
\hline C10 & 8,80 & 10,09 & 11,33 & 11,6 \\
\hline C11 & 8,95 & 9,41 & 13,37 & 10,74 \\
\hline C12 & 11,58 & 11,72 & 13,33 & 13,32 \\
\hline MÉDIA & 10,59 & 11,19 & 13,05 & 13,05 \\
\hline DP & 1,09 & 1,91 & 1,81 & 2,25 \\
\hline
\end{tabular}

I- Identificação das coelhas

CC - Corticosteróide

SS - Solução Salina

DP - Desvio Padrão 
II - QUADRO 4: Comprimento longitudinal de cada tíbia e fêmur das coelhas tratadas a base de corticóide (GE1T e GE1F) e solução salina (GC1T e GC1F).

\begin{tabular}{|c|c|c|c|c|}
\hline \multirow{2}{*}{ I } & \multicolumn{2}{|c|}{ TÍBIA } & \multicolumn{2}{c|}{ FEMUR } \\
\cline { 2 - 5 } & $\begin{array}{c}\text { CC } \\
\text { (mm) }\end{array}$ & $\begin{array}{c}\text { SS } \\
(\mathbf{m m})\end{array}$ & $\begin{array}{c}\text { CC } \\
\text { (mm) }\end{array}$ & $\begin{array}{c}\text { SS } \\
\text { (mm) }\end{array}$ \\
\hline C1 & 105 & 111 & 94 & 97 \\
\hline C2 & 112 & 114 & 98 & 93 \\
\hline C3 & 111 & 111 & 97 & 96 \\
\hline C4 & 109 & 116 & 98 & 96 \\
\hline C5 & 103 & 113 & 93 & 100 \\
\hline C6 & 101 & 104 & 90 & 92 \\
\hline C7 & 109 & 107 & 97 & 96 \\
\hline C8 & 104 & 107 & 97 & 95 \\
\hline C9 & 108 & 110 & 96 & 97 \\
\hline C10 & 106 & 109 & 90 & 93 \\
\hline C11 & 110 & 108 & 98 & 96 \\
\hline C12 & 112 & 113 & 95 & 96 \\
\hline MÉDIA & 107 & 110 & 95 & 96 \\
\hline DP & 4 & 3 & 3 & 2 \\
\hline
\end{tabular}

I- Identificação das coelhas

CC - Corticosteróide

SS - Solução Salina

DP - Desvio Padrão 
III - QUADRO 5- Comprimento circunferencial de cada tíbia e fêmur das coelhas tratadas a base de corticóide (GE1T e GE1F) e solução salina (GC1T e GC1F).

\begin{tabular}{|c|c|c|c|c|}
\hline \multicolumn{3}{|c|}{ COMPRIMENTO CIRCUNFERENCIAL } \\
\hline \multirow{2}{*}{ I } & \multicolumn{2}{|c|}{ TÍBIA } & \multicolumn{2}{c|}{ FEMUR } \\
\cline { 2 - 5 } & $\begin{array}{c}\text { CC } \\
\text { (mm) }\end{array}$ & $\begin{array}{c}\text { SS } \\
(\mathbf{m m})\end{array}$ & $\begin{array}{c}\text { CC } \\
\text { (mm) }\end{array}$ & $\begin{array}{c}\text { SS } \\
\text { (mm) }\end{array}$ \\
\hline C1 & 32 & 33 & 29 & 33 \\
\hline C2 & 32 & 32 & 23 & 31 \\
\hline C3 & 29 & 29 & 34 & 33 \\
\hline C4 & 26 & 27 & 29 & 32 \\
\hline C5 & 29 & 31 & 31 & 34 \\
\hline C6 & 30 & 25 & 27 & 27 \\
\hline C7 & 26 & 33 & 29 & 27 \\
\hline C8 & 34 & 37 & 33 & 34 \\
\hline C9 & 28 & 29 & 30 & 31 \\
\hline C10 & 25 & 27 & 28 & 29 \\
\hline C11 & 27 & 26 & 29 & 31 \\
\hline C12 & 30 & 31 & 30 & 28 \\
\hline MÉDIA & 29,0 & 30,0 & 29,3 & 30,8 \\
\hline DP & 2,7 & 3,5 & 2,8 & 2,4 \\
\hline
\end{tabular}

I- Identificação das coelhas

CC - Corticosteróide

SS - Solução Salina

DP - Desvio Padrão 
IV - QUADRO 6: Deflexão no limite de proporcionalidade de cada tíbia e fêmur das coelhas tratadas a base de corticóide (GE1T e GE1F) e solução salina (GC1T e GC1F).

\begin{tabular}{|c|c|c|c|c|}
\hline \multirow{2}{*}{ DEFLEXÃO NO LIMITE DE PROPORCIONALIDADE } \\
\hline \multirow{2}{*}{ I } & \multicolumn{2}{|c|}{ TÍBIA } & \multicolumn{2}{c|}{ FEMUR } \\
\cline { 2 - 5 } & $\begin{array}{c}\text { CC } \\
\text { (mm) }\end{array}$ & $\begin{array}{c}\text { SS } \\
(\mathbf{m m})\end{array}$ & $\begin{array}{c}\text { CC } \\
(\mathbf{m m})\end{array}$ & $\begin{array}{c}\text { SS } \\
(\mathbf{m m})\end{array}$ \\
\hline C1 & 1,35 & 1,25 & 0,75 & 0,95 \\
\hline C2 & 1,55 & 2,00 & 1,05 & 1,05 \\
\hline C3 & 0,75 & 1,15 & 0,65 & 0,55 \\
\hline C4 & 1,10 & 1,00 & 0,55 & 0,50 \\
\hline C5 & 1,25 & 1,10 & 0,45 & 0,50 \\
\hline C6 & 1,10 & 0,65 & 0,75 & 0,45 \\
\hline C7 & 1,00 & 0,90 & 0,45 & 0,70 \\
\hline C8 & 1,05 & 1,10 & 0,50 & 0,90 \\
\hline C9 & 1,20 & 1,15 & 1,00 & 1,10 \\
\hline C10 & 1,05 & 1,25 & 1,25 & 0,90 \\
\hline C11 & 1,30 & 1,20 & 1,15 & 1,20 \\
\hline C12 & 1,10 & 1,10 & 0,95 & 1,10 \\
\hline MÉDIA & 1,15 & 1,15 & 0,79 & 0,83 \\
\hline DP & 0,20 & 0,31 & 0,28 & 0,27 \\
\hline
\end{tabular}

I- Identificação das coelhas

$\mathrm{CC}$ - Corticosteróide

SS - Solução Salina

DP - Desvio Padrão 
V - QUADRO 7: Carga no limite de proporcionalidade de cada tíbia e fêmur das coelhas tratadas a base de corticóide (GE1T e GE1F) e solução salina (GC1T e GC1F).

\begin{tabular}{|c|c|c|c|c|}
\hline \multicolumn{2}{|c|}{ CARGA NO LIMITE DE PROPORCIONALIDADE } \\
\hline \multirow{2}{*}{ I } & \multicolumn{2}{|c|}{ TÍBIA } & \multicolumn{2}{c|}{ FEMUR } \\
\cline { 2 - 5 } & CC (N) & SS (N) & CC (N) & SS (N) \\
\hline C1 & 230 & 293 & 232 & 253 \\
\hline C2 & 226 & 341 & 125 & 203 \\
\hline C3 & 203 & 295 & 253 & 172 \\
\hline C4 & 331 & 229 & 256 & 157 \\
\hline C5 & 256 & 407 & 149 & 189 \\
\hline C6 & 340 & 173 & 277 & 126 \\
\hline C7 & 239 & 217 & 156 & 236 \\
\hline C8 & 290 & 292 & 164 & 202 \\
\hline C9 & 409 & 325 & 326 & 387 \\
\hline C10 & 313 & 195 & 326,76 & 168,14 \\
\hline C11 & 245 & 211 & 242 & 273 \\
\hline C12 & 264 & 250 & 254 & 273 \\
\hline MÉDIA & 278,8 & 269,0 & 230,1 & 219,9 \\
\hline DP & 59,6 & 68,7 & 67,5 & 70,2 \\
\hline
\end{tabular}

I- Identificação das coelhas

CC - Corticosteróide

SS - Solução Salina

DP - Desvio Padrão 
VI - QUADRO 8: Rigidez de cada tíbia e fêmur das coelhas tratadas a base de corticóide (GE1T e GE1F) e solução salina (GC1T e GC1F).

\begin{tabular}{|c|c|c|c|c|}
\hline \multicolumn{5}{|c|}{ RIGIDEZ } \\
\hline \multirow{2}{*}{ I } & \multicolumn{2}{|c|}{ TÍBIA } & \multicolumn{2}{c|}{ FEMUR } \\
\cline { 2 - 5 } & $\begin{array}{c}\text { CC } \\
\left.\text { ( } 10^{3} \mathbf{N} / \mathbf{m}\right)\end{array}$ & $\begin{array}{c}\text { SS } \\
\left(\times 10^{3} \mathbf{N} / \mathbf{m}\right)\end{array}$ & $\begin{array}{c}\text { CC } \\
\left(\times 10^{3} \mathbf{N} / \mathbf{m}\right)\end{array}$ & $\begin{array}{c}\text { SS } \\
\left(\times 10^{3} \mathbf{N} / \mathbf{m}\right)\end{array}$ \\
\hline C1 & 217 & 233 & 309 & 313 \\
\hline C2 & 194 & 339 & 272 & 365 \\
\hline C3 & 268 & 254 & 385 & 308 \\
\hline C4 & 299 & 226 & 461 & 309 \\
\hline C5 & 204 & 367 & 326 & 373 \\
\hline C6 & 307 & 262 & 366 & 275 \\
\hline C7 & 237 & 238 & 341 & 235 \\
\hline C8 & 274 & 263 & 323 & 222 \\
\hline C9 & 198 & 280 & 324 & 211 \\
\hline C10 & 296 & 155 & 259 & 185 \\
\hline C11 & 187 & 173 & 209 & 226 \\
\hline C12 & 238 & 225 & 246 & 265 \\
\hline MÉDIA & 243 & 251 & 318 & 274 \\
\hline DP & 42 & 57 & 65 & 58 \\
\hline
\end{tabular}

I- Identificação das coelhas

CC - Corticosteróide

SS - Solução Salina

DP - Desvio Padrão 
VII - QUADRO 9. Carga aplicada máxima de cada tíbia e fêmur das coelhas tratadas a base de de corticóide (GE1T e GE1F) e solução salina (GC1T e GC1F).

\begin{tabular}{|c|c|c|c|c|}
\hline \multicolumn{5}{|c|}{ CARGA MÁXIMA } \\
\hline \multirow{2}{*}{ I } & \multicolumn{2}{|c|}{ TÍBIA } & \multicolumn{2}{c|}{ FEMUR } \\
\cline { 2 - 5 } & CC (N) & SS (N) & CC (N) & SS (N) \\
\hline C1 & 268,7 & 293,0 & 263,0 & 227,9 \\
\hline C2 & 261,8 & 350,4 & 227,0 & 331,8 \\
\hline C3 & 296,5 & 310,0 & 265,9 & 272,6 \\
\hline C4 & 366,2 & 246,9 & 419,9 & 291,0 \\
\hline C5 & 262,0 & 409,9 & 257,5 & 259,9 \\
\hline C6 & 381,0 & 259,0 & 399,0 & 268,0 \\
\hline C7 & 239,5 & 236,8 & 275,7 & 289,9 \\
\hline C8 & 297,8 & 299,0 & 284,0 & 337,0 \\
\hline C9 & 409,0 & 328,0 & 333,0 & 387,0 \\
\hline C10 & 317,0 & 208,0 & 326,7 & 195,9 \\
\hline C11 & 245,0 & 219,0 & 249,6 & 272,9 \\
\hline C12 & 292,0 & 269,0 & 258,5 & 273,0 \\
\hline MÉDIA & $\mathbf{3 0 3 , 1}$ & $\mathbf{2 8 5 , 8}$ & $\mathbf{2 9 6 , 7}$ & $\mathbf{2 8 8 , 1}$ \\
\hline DP & $\mathbf{5 5 , 3}$ & $\mathbf{5 8 , 5}$ & $\mathbf{5 8 , 2}$ & $\mathbf{4 7 , 3}$ \\
\hline
\end{tabular}

I- Identificação das coelhas

CC - Corticosteróide

SS - Solução Salina

DP - Desvio Padrão 
VIII - QUADRO 10. Resiliência de cada tíbia e fêmur das coelhas tratadas a base de corticóide (GE1T e GE1F) e solução salina (GC1T e GC1F).

\begin{tabular}{|c|c|c|c|c|}
\hline \multirow{5}{*}{ I } & \multicolumn{2}{|c|}{ TÍBIA } & \multicolumn{2}{c|}{ FEMUR } \\
\cline { 2 - 5 } & $\begin{array}{c}\text { CC } \\
\text { (x10 }\end{array}$ & $\begin{array}{c}\text { SS } \\
\left(\mathbf{x 1 0 ^ { - 3 }} \mathbf{~ J )}\right.\end{array}$ & $\begin{array}{c}\text { CC } \\
\left(\mathbf{x 1 0}^{-3} \mathbf{J}\right)\end{array}$ & $\begin{array}{c}\text { SS } \\
\left(\mathbf{x 1 0 ^ { - 3 }} \mathbf{~ J )}\right.\end{array}$ \\
\hline C1 & 119 & 182 & 87 & 100 \\
\hline C2 & 128 & 169 & 27 & 55 \\
\hline C3 & 75 & 168 & 81 & 46 \\
\hline C4 & 165 & 114 & 70 & 39 \\
\hline C5 & 128 & 222 & 33 & 47 \\
\hline C6 & 186 & 55 & 103 & 28 \\
\hline C7 & 118 & 108 & 35 & 82 \\
\hline C8 & 151 & 159 & 40 & 90 \\
\hline C9 & 142 & 185 & 162 & 124 \\
\hline C10 & 163 & 121 & 203 & 75 \\
\hline C11 & 158 & 125 & 138 & 162 \\
\hline C12 & 144 & 136 & 119 & 149 \\
\hline MÉDIA & 139,8 & 145,3 & 91,5 & 83,1 \\
\hline DP & 28,9 & 44,4 & 56,0 & 43,8 \\
\hline
\end{tabular}

I- Identificação das coalhas

CC - Corticosteróide

SS - Solução Salina

DP - Desvio Padrão 
FOLHA ENSAIO MECANICO 
FOLHA ENSAIO MECANICO 


\section{0 - REFERÊNCIAS BIBLIOGRÁFICAS}

ADACHI J. D. Corticosteroid-Induced Osteoporosic. Int J Fertil Womens Med. United States, v. 46, n. 4, jul-aug., p. 190-205, 2001.

AFIFI, A K.;BERGMAN, R.A Steroid myophaty: a study of the evolution of the muscle lesion in rabbits. Johns Hopkins Med J, Baltimore, v. 124, n. 6, p. 66-86, 1969.

BHATTOA, H. P.; BETTEMBUK, P.; BALOGH, A.; SZEGEDI, G.; KISS, E. Bone mineral density in women with systemic lupus erythematosus. Clin Rheumatol, Belgium, v. 21, n. 2, May, p.135-41, 2002.

CAPACCIO, J. D.; GALASSI, T.M.; HICKSON, C.H. Unaltered power and endurance followihg glucocorticoid-induced muscle atrophy. Med Sci Sports Exerc, Madison, v.17, n 3, p. 380-384, 1985.

COMMES, E.N. Corticosteroid myophaty. Ann Rheum Dis, London, v. 24, p. 465-472, 1965.

CRANNEY, A.; WELCH, V.; ADACHI, J. D. HOMIK, J.; SHEA, B.; SUAREZALMAZOR, M. E.; TUGWELL, P.; WELLS, G. Calcitonin for the treatment and prevention of corticosteroid-induced osteoporosis. Cochrane Database System Review, Ottawa, v.2, p.315-345, 2000.

D'AGOSTINO, A .N.; CHIGA, M. Cortisone myopaty in rabbits, a light and electron microscopic study. Neurology, Minneapolis, v.16, p. 257-263, 1966 
EBERHARDT, A. W.; JONES, A. Y.; BLAIR, H. C. Regional trabecular bone matrix degeneration and osteocyte death in femora of glucocorticoid Treated rabbits. Endocrinlogy. V.142, n.3, p.1333-1340, 2001.

EVANS, F.G. Mechanical properties and histology of cortical bone from younger and older men. Anatomical Record, v.8, p.1-12, 1965.

FONTOURA FILHO, C. Ensaio de cisalhamento na placa de crescimento proximal da tíbia de ratas em idades diferentes. 1995. p.54 Dissertação de Mestrado. Faculdade de Medicina de Ribeirão Preto da Universidade de São Paulo, Ribeirão Preto.

GILMAN, A.; G. As Bases Farmacológicas da Terapêutica. $9^{a}$ Ed., Rio de Janeiro, McGraw-Hill, 1996, 1436p.

HALL, S.J. Biomecânica Básica. $3^{\mathrm{a}}$ Ed., Rio de Janeiro, Guanabara Koogan, cap.2, p. 64-65, 1991.

HAMILL, J.; KNUTZEN K. M. Bases Biomecânica do Movimento Humano. São Paulo, Manole, 1999.

HANLEY, D. A.; IOANNIDIS, G.; ADACHI, J. D. Etridronate therapy in the treatment and prevention of osteoporosis. J Clin Densitometry, Totowa, v. 3, n. 1, p.79-95, 2000.

HAYES, W.C.; CARTER, D.R. Biomechanics of bone. In. Skeletal Reserch, SIMMONS, D.J.; KUNIN, A.S. Academic Press, New York, n.1, p.231-235, 1971.

HOGAN, H. A.; RUHMANN, S. P.; SAMPSON, W. The mechanical properties of cancellous bone in the proximal tibia of ovariectomized rats. $\mathbf{J}$ Bone Miner Res. v.15, n.2, p.284-292, 2000.

HUANG, W. H. \& ZHENG, M. H. Steroid Hormones and Bone. J Histology and Histopatology. Nederlands, v. 14, p.1257-1268, 1999.

JOY, M. S.; NEYHART, C. D.; DOOLEY, M. A. A multidisciplinary renal clinic for corticosteroid-induced bone disease. Pharmacotherapy, v.20, p.206-216, 2000.

JUNQUEIRA, L. C.; CARNEIRO, J. Histologia Básica. 9a..Ed., Rio de Janeiro, Guanabara Koogan, 1999.

LANNA, C. M. M.; MONTENEGROJR., R.M.; PAULA, F.J.A. Pathophysiology of corticosteroid-induced osteoporosis. Arq. Bras. Endocrinol Metab, São Paulo, v.47, n.1, p.09-18, Feb, 2003.

LEE, K. E. \& PELKER, R.R. Effect of freezing on histologyc and biomechanical failure patterns in the rabbit capital femoral growth plate $\mathbf{J}$ Orthop Res., v.3, p.514, 1985. 
LLOYD M. E.; DAVITT, S.; HALL, J.R. Bilateral tibia and fibula fractures in a patient with rheumatoid arthritis. Clin Rheumatol. Belgium, v.20, n.4, p.2702, 2001.

NAVA, S.; GAYAN-RAMIREZ, G.; ROLLIER, H.; BISSCHOP, A.; DOM, R. DE BOCK, V.; DECRAMER, M. Effects of acute steroid administration on ventilatory and pheripheral muscles in rats. Am J Respir Crit Care Med. New York, v.153, p.1888-1896, 1996.

NEGRI, A. L.; PLANTALECH, L. C.; RUSSO PICASSO, M. F.; OTERO, A.; SARLI, M. Osteoporosis postransplante. Medicina, Buenos Aires, v.59, n.6, p.777-786, 1999.

ORSTAVIK, R.E.; HAUGEBERG, G.; UHLIG, T.; FALCH, J. A.; HALSE, J.I.; HOISETH, A.; LILLEAS, F.; KVIEN, T. K. Vertebral deformities in 229 female patients with rheumatoid arthritis: association with clinical variables and bone mineral density. Arthritis Rheum. Oslo, v.49, n.3, p.355-360, Jun, 2003.

PESSAN, V. J. Ensaio de Flexão em Três Pontos nas Faces Anterior e Posterior de Fêmures de Ratas, em duas Fases Diferentes de Crescimento. 1996.51p. Dissertação de Mestrado em Bioengenharia Escola de Engenharia de São Carlos e Faculdade de Medicina de Ribeirão Preto da Universidade de São Paulo, Ribeirão Preto..

RAISZ, L.G.; LUKERT, B.P. Glucocorticoid-induced osteoporosis. Rheum Dis Clin North Am. V.20, n.3, p.629-650, Aug, 1994.

RANG, H. P.; DALE, M.M.; RITTER, J.M. O sistema endócrino. In: Farmacologia, Rio Janeiro: Guanabara Koogan, 2001,703p.

REID, D. M. Efficacy and safety of daily risedronate in the treatment of corticosteroid-induced osteoporosis in men and women: a randomized trial. $\mathbf{J}$ Bone Miner Res, Cambridge, v.15, n.6, p.1006-1013, 2000.

REILLY, D. T. \& BURSTEIN, A. H.: The Mechanical Properties of cortical bone. J Bone Joint Surg., v.56, p.1001-1022, 1974.

SALTER, R. B. Distúrbios e lesões do sistema músculo-esquelético. $2^{\mathrm{a}}$ Ed., Rio de Janeiro, Medsi, 556p, 1985.

SAMBROOK, P. N. Inhaled corticosteroids, bone density and risk of fracture [comment ]. Lancet, London, v.355, n.9213, p.1385, 2000.

SEDLIN, E. D. \& HIRSCH, C. Factors affecting the determination of the phisical properties of femoral cortical bone. Acta Orthop Scand., v.37, p.2948, 1966. 
SELBY, P. L.; HALSEY, J.P.; ADMAS, K. R.; KLIMIUK, P.; KNIGHT, S. M.; PAL, B.; STEWART, I. M.; SWINSON, D. R. Corticosteroids do not alter the threshold for vertebral fracture. J Bone Miner Res, Cambridge, v. 15, n. 5, p. 952-956, May, 2000.

SHIMANO, A.C.; SHIMANO, M. Ensaios tecnológicos de materiais biológicos. In: CONGRESSO BRASILEIRO DE ENGENHARIA BIOMÉDICA, 1., 2000, Florianópolis. Anais... Florianópolis: CBEB, 2000. v.1, p.15-21.

SILVA A. V. Modelo de Simulação de Microgravidade e seu Efeito em Algumas Propriedades Mecânicas do Osso do Rato. 2002. 67p. Dissertação de Mestrado em Bioengenharia - Escola de Engenharia de São Carlos e Faculdade de Medicina de Ribeirão Preto da Universidade de São Paulo, Ribeirão Preto.

SILVA, E. C. Aspectos Biomecânicos Musculares Relacionados à Administração Experimental de Corticosteróide Sistêmico. 2002.80p. Dissertação de Mestrado em Bioengenharia - Escola de Engenharia de São Carlos e Faculdade de Medicina de Ribeirão Preto da Universidade de São Paulo, Ribeirão Preto.

SILVA, I.R.S. Influência dos Corticosteróides nas Propriedades Mecânicas da Traquéia de Coelhas Albinas. 2003. 65p. Dissertação de Mestrado em Bioengenharia - Escola de Engenharia de São Carlos e Faculdade de Medicina de Ribeirão Preto da Universidade de São Paulo, Ribeirão Preto.

SOBOTTA, J. - Atlas de Anatomia Humana. 20ª Ed. Rio de Janeiro, Guanabara Koogan, 1995, v.2. 399p.

SOUZA, S. A. Ensaios Mecânicos de Materiais Metálicos. $5^{\mathrm{a}}$ Ed. São Paulo,Edgard. Blucher Ltda., 1977. 286p.

SPENCE, A. P. Anatomia Humana Básica. $2^{a}$ Ed. São Paulo, Manole, 1991. 713p.

STAFFORD L. BLEASEL, J. GILES, A.; HANDELSMAN D. Androgen deficiency and bone mineral density in men with rheumatoid arthritis. $J$ Rheumatol, Canada, v. 27, n. 12, p. 2786-90, Dec., 2000.

YAMAMOTO, T.; IRISA, T.; SUGIOKA, Y.; SUEISHI, K. Effects of pulse methylprednisolone on bone and marrow tissues: corticosteroid-induced osteonecrosis in rabbits. Arthritis Rheum, v.40, p.2055-2064, 1997.

YASUDA, S.; KOGAWA, M.; WADA, S. Glucocorticoid induced osteoporosis. Nipón Rinsho, v.61, n.2, p.280-286, Feb, 2003. 